\title{
Developing Dynamic Digital Image Correlation Technique to Monitor Structural Damage of Old Buildings under External Excitation
}

\author{
Ming-Hsiang Shih ${ }^{1}$ and Wen-Pei Sung ${ }^{2}$ \\ ${ }^{1}$ Department of Civil Engineering, National Chi Nan University, Puli, Nantou 545, Taiwan \\ ${ }^{2}$ Department of Landscape Architecture, Integrated Research Center for Green Living Technologies, National Chin-Yi University, \\ Taichung 41170, Taiwan
}

Correspondence should be addressed to Wen-Pei Sung; wps@ncut.edu.tw

Received 4 February 2014; Revised 11 June 2014; Accepted 15 June 2014; Published 15 July 2014

Academic Editor: Longjun Dong

Copyright (C) 2014 M.-H. Shih and W.-P. Sung. This is an open access article distributed under the Creative Commons Attribution License, which permits unrestricted use, distribution, and reproduction in any medium, provided the original work is properly cited.

\begin{abstract}
The capacity of buildings to resist external excitation is an important factor to consider for the structural design of buildings. When subject to external excitation, a building may suffer a certain degree of damages, and its residual capacity to resist external excitation cannot be evaluated. In this research, dynamic digital image correlation method combined with parameter evaluation available in system identification is used to evaluate the structural capacity to resist external excitation. The results reveal possible building latent safety problems so that timely structural reinforcement or dismantling of the building can be initiated to alleviate further damages. The results of experiments using the proposed method conform to the results obtained using the conventional method, but this method is more convenient and rapid than the latter in the subsequent procedure of data processing. If only the frequency change is used, the damages suffered by the building can be detected, but the damage location is not revealed. The interstory drift mode shape (IDMS) based on the characteristic of story drift has higher sensitivity than the approximate story damage index (ADSI) method based on modal frequency and vibration type; however, both indices can be used to determine the degree and location of building damages.
\end{abstract}

\section{Introduction}

The life cycle of a civil engineering structure includes the steps of development and construction, application and maintenance, and demolition and removal. Enhancing the functional characteristics of materials and applying new construction technology during the construction period will improve the quality, the functions, and the safety of the structure. However, before a structure reaches its designed life cycle, its structural functions need to be evaluated during the various stages of application; the results will be referenced for conducting structural maintenance and/or reinforcement. In recent years, the record breaking earthquakes of Richter Scale 9 and the aftermath tsunami such as those that have occurred in Indonesia and Japan are profoundly impressive $[1,2]$. The global warming will lead to more natural disasters in the future so that the evaluation of building capability to resist external excitation should be emphasized for the safety of the occupants. Although a building has been designed to resist external excitation of certain intensities, it may suffer a certain degree of damage to weaken the building and reduce its quake-resisting capability. In particular, Taiwan is located in the Pacific seismic belt and there are many old buildings in Taiwan constructed before 1970s. Not only these kind of old buildings are threatened by earthquake seriously, but also many existed buildings are menaced the safety of structure by strong earthquake. Hence, conducting the evaluation of the capability of a building to resist external excitation will 


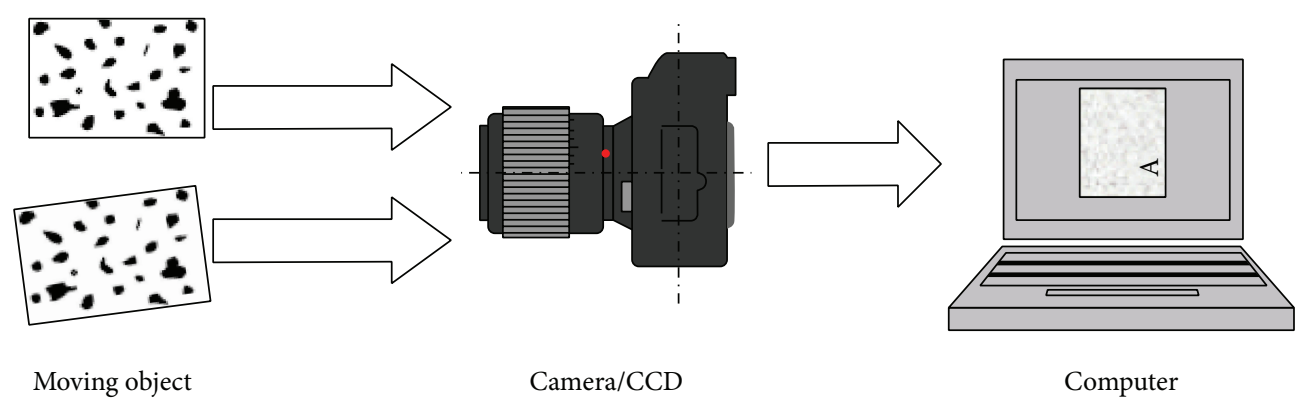

FIGURE 1: The experimental setup for 2D digital image correlation method.

allow timely remedies such as structural reinforcement or even dismantling the building to alleviate damages to be caused by future quake. The response of a building to external vibration is extremely complicated; its prediction must consider forecasting the quake characteristics and the building nonlinear responses to quake and their mutual correlations in addition to predicting erratic human factors. Hence, detailed estimation of the building quake-resisting capability of a building and its expected useful life is extremely difficult; scholars and civil engineers in the world continually engage in developing quake-resisting buildings in order to safeguard life and property of occupants.

The technology for building diagnoses is mostly based on the use of sensors (e.g., accelerometer, speedometer, strainometer, and global positioning system (GPS), among many others) to collect the building dynamic information and data [3-12]. Some noise signals from these dynamic test will affect the analysis precision of these kind of data. Therefore, some de-noise methods such as a wavelet based multistep filtering method and improved particle filtering algorithms are proposed to filter out the noise from dynamic test $[13,14]$. Then, the results are applied to develop mathematical, for example, models for identifying the building dynamic parameters such as system matrices of structure or modal parameters of structures in a process known as system identification [15-18]. Pertinent structural features such as natural frequency, mode shape, and damping ratios, among many others, can be isolated and identified using the above models to develop quantitative damage index. The time-dependent variation of damage index is the basis for conducting building diagnoses.

Some traditional measuring methods are applied to detect the building responses of dynamic parameters. These methods need to use many sensitive instruments to provide the needed information. Nevertheless, the cost involved is too high to be practical. The digital image correlation (DIC) method, proposed by our research team, is a new optical measurement technique to offer low-cost strain distribution with high precision. In this study, this DIC method will be developed based on developing and applying the digital photographing technology to monitor the building dynamic response under excitation of various external earthquake records to test and verify the precision of this proposed method in monitoring, building, deformation, and movement. Therefore, in this research, the "dynamic digital image correlation, DIC" method will be developed into a technology for dynamic monitoring of structures based on digital images. The measurable data on characteristic building response data and features, for example, resonant frequencies, MAC, COMAC, mode shape curvatures, dynamic flexibility, damping, and so forth will be excerpted to identify the degree and location of building damages. The results obtained using the proposed method will be compared with those reported by previous researchers in order to verify the validity and applicability of this dynamic method for timely diagnoses of building health.

\section{Methodology-Dynamic Digital Image Correlation Method}

The dynamic digital image correlation method uses optical equipment to record the process of the object deformation and movement in digital film. These photographs can use the "Finding Algorithm" to develop the technology of dynamic digital image correlation method and dynamic DIC for comparing the partial relativity of two images towards reflection before and after structural deformation or movement; the experimental setup is shown in Figure 1. The comparison results can be used to analyze the relative displacement and deformation of the object between the two moments. This dynamic DIC technique is basically taken as the foundation of "search to perform mathematical calculations." The main analysis concept is based on the finite element method, the images are divided into small mesh; the total value of the mesh gray scale values of mesh in original image can be compared with those in the image after transformation so that the corresponding location of a selected mesh in the deformed image can be identified. The two-dimensional DIC method is suitable for the plane strain test or the test without obvious out-of-plane displacement [19]. But some characteristics of structural dynamic response contain outof-plane displacement or the specimen surface is not a plane. Therefore, the three-dimensional DIC method is necessary for the measurement. Traditionally, more than one camera needs to be installed to capture images to conduct threedimensional image analysis process; however, the analytical parameters of this method are correlated and excessive. 


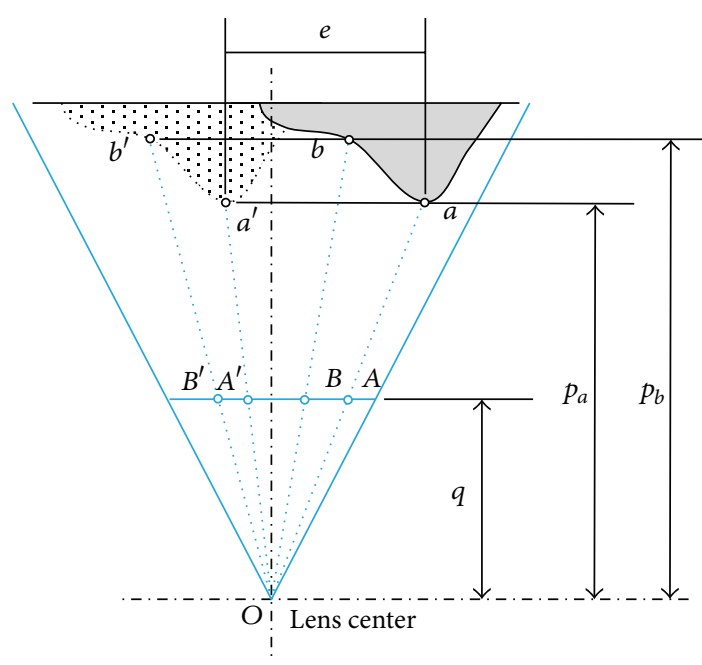

FIGURE 2: The parallax phenomenon caused by the difference object distance [20].

Therefore, the simplest DIC method based on a single digital camera with 3D digital images is proposed by Shih et al. [20].

2.1. A Single Digital Camera for 3D Digital Images [20]. If the horizontal distance for the camera to move to the right (or the object to move to the left) is "e," the horizontal displacements

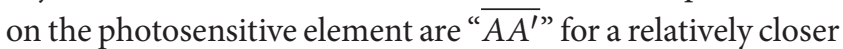

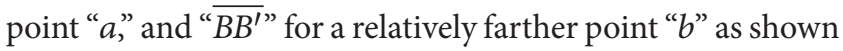
in Figure 2.

The geometric relationship is

$$
\begin{aligned}
& \overline{A A^{\prime}}=\left(\frac{q}{p_{a}}\right) e, \\
& \overline{B B^{\prime}}=\left(\frac{q}{p_{b}}\right) e,
\end{aligned}
$$

where $q, p_{a}$, and $p_{b}$ are the distance between center of lens and photosensitive element, point $a$, and point $b$, respectively. The horizontal movement on the sensing element is expressed in pixels; thus,

$$
N_{A A^{\prime}}=\gamma\left(\frac{q}{p_{a}}\right) e,
$$

where $\gamma$ is the number of pixels of a unit sensing element in pixels $/ \mathrm{mm}$ and $N_{A A^{\prime}}$ is the horizontal displacement of " $a$ " in pixels. Because the correct values of $\gamma$ and $q$ are unknown, these two parameters can be combined into a single parameter " $\Lambda$." Hence,

$$
\Lambda=\gamma q
$$

Equation (4) can be rewritten as

$$
\Lambda=\frac{N_{A A^{\prime}} p_{a}}{e} .
$$

Once the calibrated value of $\Lambda$ can be found using regression analyses; the distance between two points can be calculated as follows:

$$
p_{b}=\frac{\Lambda}{N_{B B^{\prime}}} e .
$$

Knowing the distance between the two points, the horizontal and vertical distances of the object to the lens center $(x, y)$ can be found. Equation (5) can be used to calculate the distance of any object " $b$," and the theoretical error can be estimated by differentiating the equation:

$$
d p_{b}=\frac{-\Lambda e}{N_{B B^{\prime}}^{2}} d N_{B B^{\prime}}
$$

Equation (6) indicates that the error is inversed proportionally to the distance between the object and the camera distance. Hence, a greater camera distance will lead to more precise results. Therefore, when the camera is horizontally moved " $e$ " distance, the horizontal displacement in pixels of " $a$ " on the sensing element is $N_{A A^{\prime}}$ based on the relationship to approximate triangular form. If the horizontal coordinate of $a$ with respect to the lens center is $x_{a}$, its relationship to the photohorizontal coordinate $X_{A}$ fits the following relationship:

$$
\frac{x_{a}}{X_{A}}=\frac{e}{N_{A A^{\prime}}} .
$$

Moving the terms, one obtains

$$
x_{a}=\frac{X_{A} e}{N_{A A^{\prime}}} .
$$

Similarly,

$$
y_{a}=\frac{Y_{A} e}{N_{A A^{\prime}}} .
$$

2.2. The Three-Dimensional Dynamic DIC Method with SpineType Prism. The principal of three-dimensional DIC for using a single digital camera to photograph digital images is based on the plane geometrical images of the $3 \mathrm{D}$ object photographed from different angle, displaying these two images at the same general appearance of a picture and then assembling these two digital images in an analytical geometry as three-dimensional coordinates to be displayed as three-dimensional images. This measurement principle can be accurately applied in static deformation test. Nevertheless, this theory is not suitable for three-dimensional dynamic tests. A key point of three-dimensional DIC technique is applied a camera to capture images of object movement in the same position. If the above-mentioned method is applied directly to measure dynamic response of structure, it would result in significant analysis errors.

Therefore, a spine-type prism is proposed to separate the view axis of the digital camera into two axes which are inclined to each other in this research to conduct threedimensional dynamic digital image correlation techniques. In 


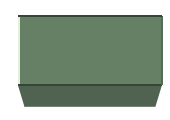

Object

Prism

Virtual image L
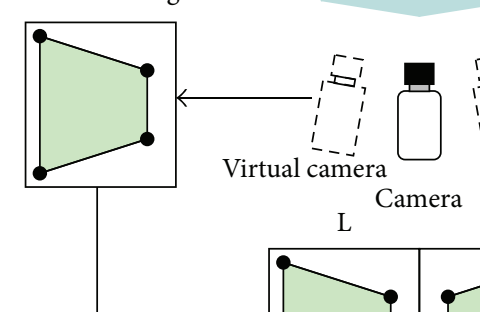

$\mathrm{L}$ $\mathrm{R}$

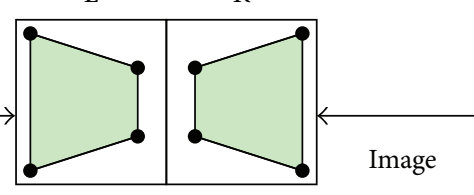

FIgURe 3: Principle of the spine-type prism for 3-dimensional DIC.

the dynamic test, digital cameras can receive two images with parallax in a single capture action. These two images with parallax are stored in the right and left parts of the sensor of the camera. The analysis principle of this proposed method is shown in Figure 3. The major advantage of this technology is the maneuverability. As long as the prism is installed on the camera, the camera can be used normally to capture images with parallax.

In order to identify the three-dimensional dynamic response of structure under excitation of external force, the hardware specifications of cameras must meet the requirement of sensitive instruments and equipment with sufficient frequency or sufficient readings for each recoding channel within a unit time. Hence, NexShot2C-2 M CMOS industrial camera, with 1/2-inch CMOS active-pixel digital image sensor, $1600 \times 1200$ dots per inch, $41 \mathrm{~Hz}$ capturing frequency, sensitization 2 mega pixels, and the highest sampling rate reaches to $5.3 \mathrm{fps}$ (frames per seconds), is used to collect the uncompressed photographs with high quality in this study. Because the recording frequency is insufficient, the scanning numbers of selecting images adjust 120 pieces, and selecting image reaches to 42 pictures per minute. Then, the collected images can be used to analyze the displacement reaction of test object by the DIC method.

\section{Damage Index}

3.1. Natural Frequency as Damage Index. When building is excited by external force, the dynamic features can be easily extracted from structural dynamic response such as natural frequency, mode shape, and damping ratios. These dynamic features can be used to establish damage index to diagnose the structural health. In this section, natural frequency variation of structure under the excitation of external force to induce structural injury is proposed to be damage index to monitor structural health.
The evaluation formula of damage index based on natural frequency is expressed as follows:

$$
\delta_{M}=1-\frac{\left(T_{0}\right)_{\text {initial }}}{\left(T_{0}\right)_{\max }}
$$

where $\left(T_{0}\right)_{\text {initial }}$ represents basic dynamic cycle of undamaged structure. $\left(T_{0}\right)_{\max }$ is the maximum basic dynamic cycle of time history of dynamic response. The value of damage index based on natural frequency is between 0 and 1.0 and represents undamaged of structure.

3.2. Approximation Story Damage Index (ASDI). Story Damage Index (SDI) applied the participative parameters from structural system such as stiffness and mass to produce structural modal parameters (eigenvalue $\lambda\left(=w^{2}\right.$ ) and mode shape $\phi$ ) and the relationship between mass of floor and stiffness to establish a Story Damage Index for assessing building damage excited by earthquake. Nevertheless, the mass of floor is hard to evaluate. Therefore, Approximation Story Damage Index (ASDI) is proposed to ignore the mass of floor. This method requires only one modal parameter to assess story damage, Wang et al. [16]. The main concept of ASDI is applied to plane structure of shear frame. The torsion coincidental effect must be considered for threedimensional structure. The damage index from frequency and modal vector of the first mode shape has been transform into summation inertia of floor to story drift mode. Then, story drift mode changes into story stiffness of structure to assess the decay of story stiffness after structural damage as an estimating index.

The evaluation formula of Approximation Story Damage Index (ASDI) is expressed as follows:

$$
\operatorname{ASDI}_{l}=1-\frac{\omega_{j}^{* 2} \sum_{i=1}^{N}\left(\phi_{i j}^{*} / \Delta \phi_{i j}^{*}\right)}{\omega_{j}^{2} \sum_{i=1}^{N}\left(\phi_{i j} / \Delta \phi_{i j}^{*}\right)},
$$

where lis degree of freedom; $N$ is total floor of structure; $\omega_{j}^{*}$ is the $j$ th natural frequency after structural damage; $\omega_{j}$ is the $j$ th natural frequency before structural damage; $\phi_{i j}^{*}$ is the mode shape of $i$ th degree of freedom of the $j$ th mode shape after structural damage; $\phi_{i j}$ is the mode shape of $i$ th degree of freedom of the $j$ th mode shape before structural damage. The value of ASDI is between 0 and 1.0 and represents undamaged of structure.

3.3. Interstory Drift Mode Shape (IDMS) as Damage Index. When structural damage happens, the stiffness of building structure drops off, affecting the displacement mode reaction of structure. Thus, IDMS is proposed to probe the relationship of structural destructiveness and variation of displacement mode to judge the structural damage on building. The ratio of story drift of the first mode used IDMS as a normalized datum value of roof before damage for comparison with IDMS as a normalized datum value of roof after damage. When the sensitivity of IDMS is higher, the probability of structural damage is higher. The definition of story drift and sensitivity of IDMS is expressed as follows. 


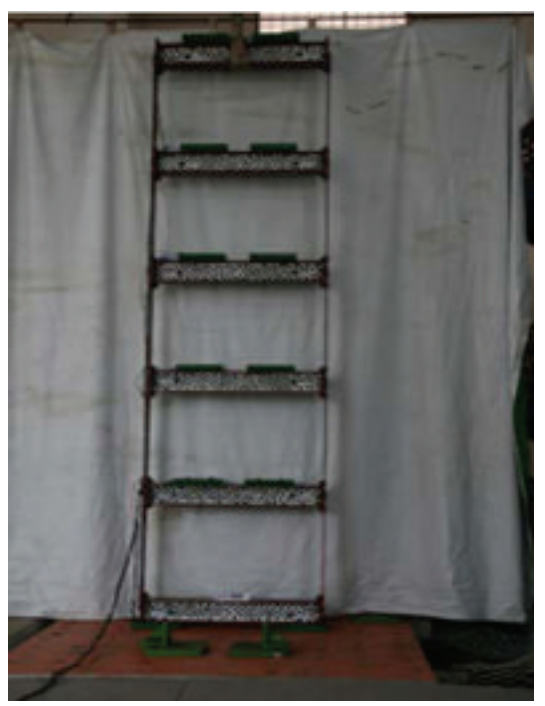

FIgURE 4: The completed five-story shearing steel structure.

Story driftis as follows:

$$
\begin{aligned}
& \delta_{i}=\operatorname{Max}\left(\Delta_{i}-\Delta_{i-1}\right), \\
& \delta_{1}=\operatorname{Max}\left(\Delta_{1}-\Delta_{G}\right),
\end{aligned}
$$

where $\delta_{i}$ is time history analysis of the maximum story drift of the $i$ th floor; $\Delta_{i}$ is time history analysis of the structural displacement history of the $i$ th floor; $\Delta_{G}$ is ground displacement.

Sensitivity of IDMS is as follows:

$$
S_{i}=\frac{D_{i}-B_{i}}{B_{i}} \times 100 \%
$$

where $S_{i}$ is the sensitivity(\%) of the story drift variation after damage of the 1st mode of the $i$ th floor of building; $D_{i}$ is the normalized story drift mode value after damage of the $i$ th floor of building; $B_{i}$ is the normalized story drift mode value before damage of the $i$ th floor of building.

\section{Experimental Setup}

The shaking table model test will be used in this research to carry out all laboratory studies. The shearing steel structural model is a five-story steel framed structure using steel with $E$ value of $2 \times 10^{11} \mathrm{~kg} / \mathrm{m}^{2}$. The net height of each story is $800 \mathrm{~mm}$ with a total building height of $5,800 \mathrm{~mm}$, width of $1,520 \mathrm{~mm}$, and depth of $400 \mathrm{~mm}$. Each story weighs $242 \mathrm{~kg}$, and total structure has a designed natural frequency of $1.076 \mathrm{~Hz}$ and the natural frequency of the second vibration mode of $3.21 \mathrm{~Hz}$. Figure 4 shows the photo of the completed five-story shearing steel structure; Figure 5 shows the installed camera and other relevant equipments. Each element used in the model structure has been carefully evaluated to check whether it reaches the yield point. If an element shows the sign of yield, it is immediately replaced in order to warrant the accuracy of

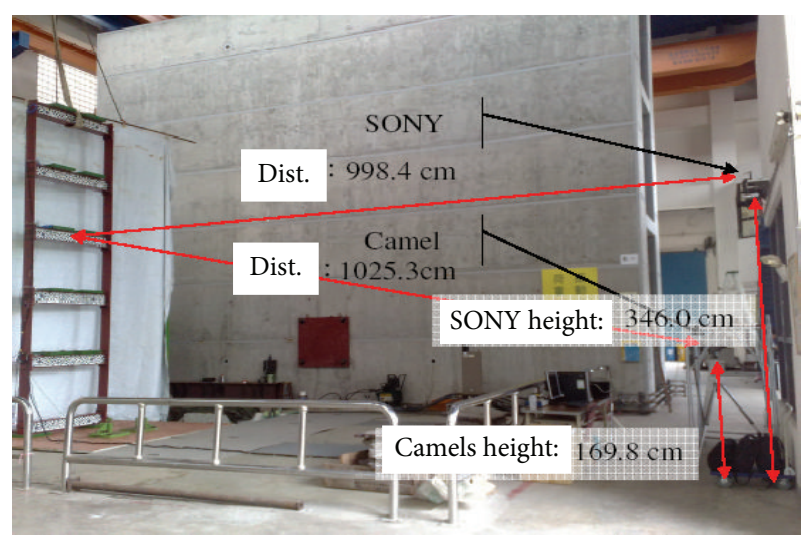

FIGURE 5: The experimental setup of installed camera and other relevant equipment.

the laboratory study results. A series of dynamic experiments have been planned; the results are compared with those obtained using accelerometer. But there are two factors: (1) the maximum throw of this test shaking table is $\pm 125 \mathrm{~mm}$; (2) test structure should remain within linear elastic range for dynamic test and it needs to be considered in this study. Therefore, the maximum acceleration should be scaled down to 15-20 gal. Actually, the purpose of this research is to obtain the modal frequencies and modes of test structure within linear elastic range. Therefore, the authenticities of earthquake records do not provide sensitivity. Otherwise, El Centro, Kobe, and TCU earthquake records are provided with characteristic of far field and near-fault earthquake. These records are applied to excite modal response of high frequencies and low frequencies of test structure. Then, white noise study is carried out in order to investigate whether the shearing steel structure is subject to environmental interference that will adversely impact the practicability of the experimental results. Table 1 lists the study plan.

4.1. System Identification Method. In this research, the method of comparing images is implemented to reveal the time-dependent variation of displacement so that using the system identification method can be used to measure the external force input and the resulting dynamic response of the structural degree of freedom for obtaining the structural mode parameters, for example, frequency $\omega$, damping ratio $\xi$, vibration mode $\phi$, and so forth. The system realization using information matrix (SRIM), which uses the system identification matrix of the measured data, is capable of identifying the system modes of multiple inputs and outputs in additional to identify the system dynamic structural matrices based on the structural system matrix. The mode parameters including frequency $(\omega)$, damping ratio $(\xi)$, and vibration mode $(\phi)$ can then be extracted from the dynamic structure of the identification of the two-stage system for evaluating the building damages. The SRIM system used in this system is based on the identification theory developed by Juang [21] to construct a broad Hankel matrix, using impulse response data, and to estimate the extendable observability 
TABLE 1: Study plan for laboratory experiment.

\begin{tabular}{|c|c|c|}
\hline Name of structure & Experimental shearing $\mathrm{s}$ & teel structure \\
\hline Shearing steel structure & Reference set (width of column) & Experimental set (width of column) \\
\hline $\begin{array}{l}\text { Normal monitoring } \\
\text { experiment }\end{array}$ & $400 \mathrm{~mm}$ & $380 \mathrm{~mm}, 360 \mathrm{~mm}, 280 \mathrm{~mm}$, and $200 \mathrm{~mm}$ \\
\hline $\begin{array}{l}\text { Data retrieving and } \\
\text { recording equipment }\end{array}$ & $\begin{array}{l}\text { Equipment for dynamic DIC techniques } \\
\text { (1) Dynamic digital device-industrial CCD } \\
\text { (2) Dynamic digital device-handy video SONY and } \\
\text { Cannon EOS digital camera } \\
\text { Traditional acceleration detecting device } \\
\text { ACC Accelerometer }\end{array}$ & \\
\hline $\begin{array}{l}\text { Location for installing the } \\
\text { data retrieving and } \\
\text { recording equipment }\end{array}$ & $\begin{array}{l}\text { DIC method } \\
\text { The experimental setup is shown in Figure } 5 \text {. All } \\
\text { dynamic responses of test structure are recorded by } \\
\text { local images of structural response } \\
\text { Data retrieving form accelerometer } \\
\text { Accelerometers are installed in each floor and base at } \\
\text { horizontal direction }\end{array}$ & \\
\hline $\begin{array}{l}\text { Input of earthquake data } \\
\text { and external force for the } \\
\text { steel structure }\end{array}$ & $\begin{array}{l}\text { Natural earthquake record } \\
\text { (1) Strong earthquake Kobe and El Centro } 1940 \\
\text { earthquake record } \\
\text { (2) Strong earthquake TCU, Chi-Chi earthquake } \\
\text { record, } 1999 \\
\text { (3) White noise } \\
\text { (4) RAMP }\end{array}$ & \\
\hline
\end{tabular}

and controllability matrices using singular value decomposition (SVD) for extracting a set of equivalent discrete time state-space equations to extract the mode parameters for the structural system matrix.

\section{Results and Discussions}

The dynamic experimental procedures to be carried out in this study must be done by overcoming difficulties encountered when implementing the traditional experimental technique; they must also be integrated with image capture and dynamic CCD transfer and analysis of image information. Additionally, the quake loading to a building is of random nature; the mode and frequency of the responsive building vibration that causes damages to the building are also of random nature. Hence, responses to external quake loading inputs using free vibration method, environmental disturbance method, and forced oscillation method are used as the inputs in order to investigate the variations of the mode and frequency of vibration for the building when it is being gradually damaged. Further, variations of the first-story column cross-sectional stiffness are investigated to simulate the influence of column stiffness on the mode and frequency of building vibration.

The reference set with width of column is $400 \mathrm{~mm}$ under excitation of various earthquake records, and the experimental set with different widths of column is $380 \mathrm{~mm}, 360 \mathrm{~mm}$, $280 \mathrm{~mm}$, and $200 \mathrm{~mm}$ under excitation of various earthquake records to obtain the dynamic responses, respectively. The detected typical dynamic responses from this proposed DIC method that used the width of column $380 \mathrm{~mm}$ as an example are shown in Figure 6. Then, all analysis results of natural frequencies, damping ratio, and mode shape of steel test building with width of column $=380 \mathrm{~mm}$ under excitation of free vibration, Kobe earthquake record, and El Centro 1940 record detected from this proposed DIC method and traditional accelerometers are listed in Table 2 as an example, respectively. All detected dynamic responses from DIC method and accelerometers are analyzed and compared with each other in Sections 5.1, 5.2, and 5.3.

The difference of natural frequencies between the test and analysis results of this proposed DIC method and those of accelerometers is about $0.02 \%-4.5 \%$. The relative errors of the 1 st mode and 2 nd mode are from $0.00 \%$ to $15.0 \%$ and from $0.00 \%$ to $12 \%$, respectively. The test results reveal that relative errors of the $3 \mathrm{rd}$ and 4 th modes are from $0.00 \%$ to $20.00 \%$ and from $0.00 \%$ to $15.00 \%$, respectively. There is a slight difference between these two methods at the 5th mode. The maximum relative error of this mode happens at the 3rd floor of shearing building under the excitation of El Centro earthquake record. Otherwise, the comparison of test and analysis results of damping ratio between the structural dynamic responses under excitation of various external forces shows that, when the test structure is under excitation of free vibration, the damping ratio between these two methods is slightly different. But, when the test structure is under excitation of various earthquake records, the difference of damping ratio at the 1st mode becomes large. Although the errors of the 3rd mode are higher than the other modes, all the mode shapes and frequencies of the test and analysis results of this proposed method are close to the test and analysis results of the structural response records of acceleration recorded by accelerometer. 


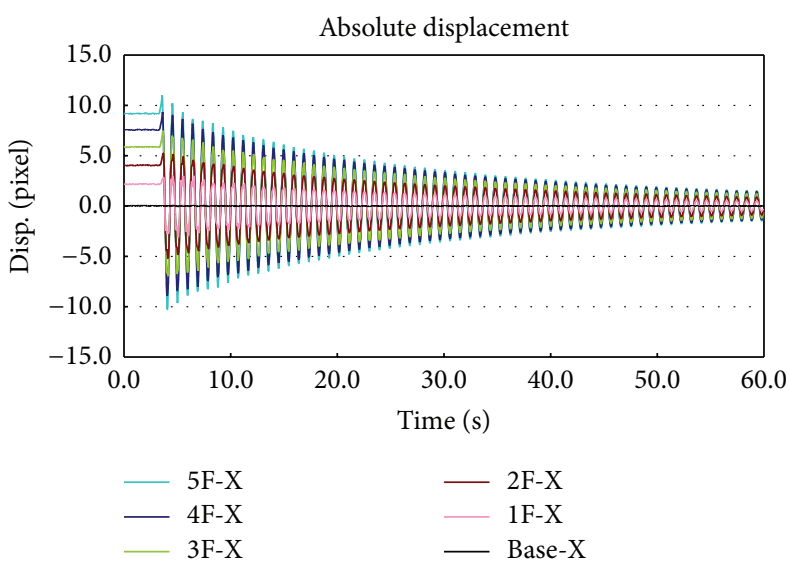

(a) Absolute displacement record

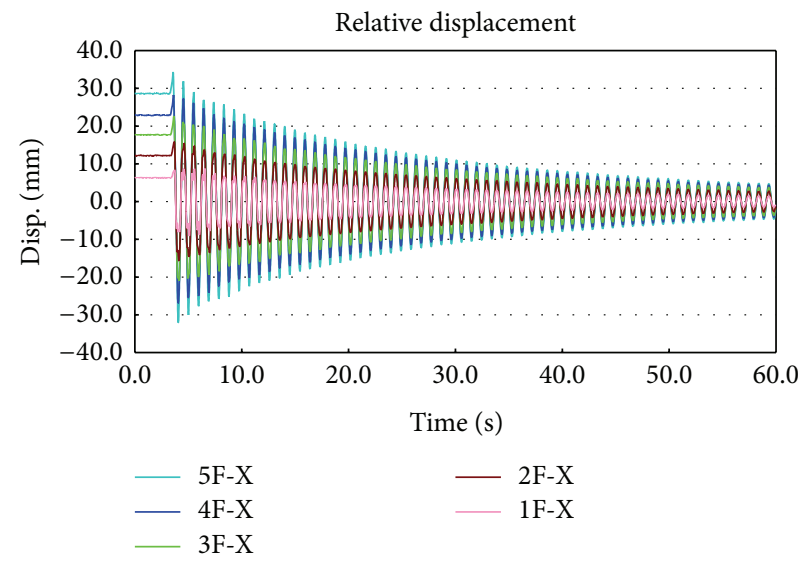

(b) Relative displacement record

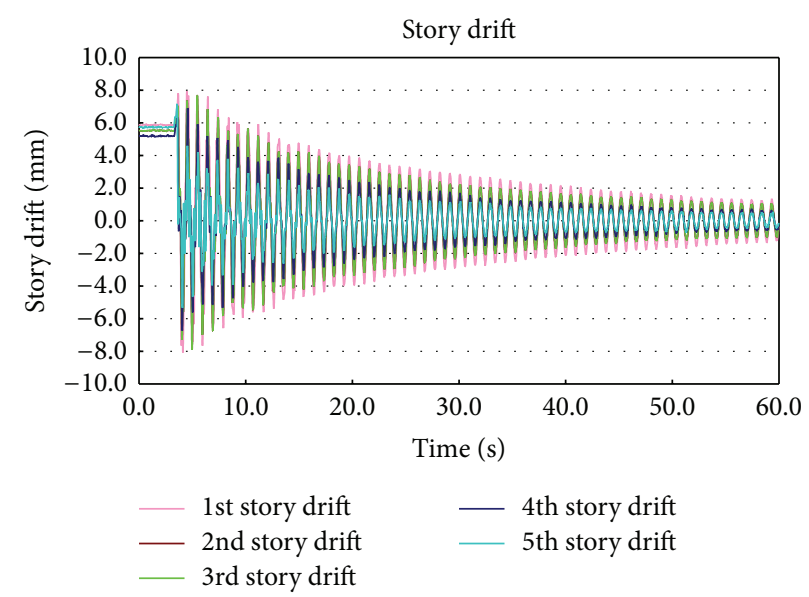

(c) Story drift record

FIGURE 6: The typical dynamic responses, detected from DIC method, with width of column $=380 \mathrm{~mm}$ under excitation of free vibration as typical responses records.

5.1. Results of Analyses Using Natural Frequency as the Characteristic Damage Indices. Figures 7, 8, 9, 10, and 11 show comparisons of the identified natural frequencies for columns of various cross-sectional sizes subject to different earthquake records, listed in Table 1 . The result shown in Figure 7 indicated that, when the steel cross-sectional area is $400 \mathrm{~mm}$, the high mode natural frequencies obtained using the method proposed in this research and the traditional method have some discrepancies mainly caused by differences between the methods used for zeroing the reference line. However, variations of the natural frequencies for buildings of different stiffness subject to various earthquake records (Figure 10 Figure 11) indicate that the method proposed in this research is capable of predicting the building natural frequency after the earthquake as precisely as the conventional method. Results of damage index analyses conducted on the above experimental results shown in Figure 12 reveal that the method proposed in this research and the conventional method will yield similar damage indices. Hence, the experimental results confirm that the damage index that is based on frequency can be used as a rapid method to evaluate the overall health of a building. When an earthquake damages the building, variations of the building stiffness that is gradually changing can be monitored so that the degree of building damage can be evaluated. However, this method is not capable of determining the location of building damage.

5.2. Analysis Results on Approximation Story Damage Index(ASDI-) Based Damage Index. Results of Approximation Story Damage Index (ASDI) that is the damage index based on characteristic modal type and frequency are shown in Figures 13-16. The free vibration ASDI for various building dimensions shown in Figure 13 reveals closer ASDI results between the method proposed in this research and the conventional method for lower ASDI levels, and vice versa; the sensitivity of the method proposed in this research is higher than the conventional method. Hence, this method is capable of detecting the degree of building damage based on ASDI for building suffering from slight damages. Figure 14 reveals that, when the EL Centro 1940 earthquake records are tested, the ASDI are closer for these two methods because of the more serious damages at the cross-section. When the cross-section dimension is $380 \mathrm{~mm}$, the ASDI for these 
TABLE 2: Test and analysis results of natural frequencies, damping ratio, and mode shape of steel test building with width of column $=380 \mathrm{~mm}$ under excitation of free vibration, Kobe earthquake record, and El Centro 1940 record.

(a)

\begin{tabular}{|c|c|c|c|c|c|}
\hline \multirow[b]{2}{*}{ Items } & \multicolumn{5}{|c|}{ Test and analysis results of free vibration traditional accelerometer } \\
\hline & 1st mode & 2nd mode & 3rd mode & 4th mode & 5th mode \\
\hline Natural frequency & 1.0743 & 3.2036 & 5.1060 & 6.5896 & 7.5249 \\
\hline Damping ratio & 0.5320 & 0.4916 & 0.4767 & 0.5022 & 0.4506 \\
\hline \multicolumn{6}{|l|}{ Mode shape } \\
\hline Base & 0 & 0 & 0 & 0 & 0 \\
\hline $1 \mathrm{~F}$ & 0.3155 & 0.7997 & 1 & 0.9547 & 0.5127 \\
\hline $2 \mathrm{~F}$ & 0.5912 & 1 & 0.1928 & -0.8875 & -0.8923 \\
\hline $3 \mathrm{~F}$ & 0.7940 & 0.4850 & -0.9206 & -0.1499 & 1 \\
\hline $4 \mathrm{~F}$ & 0.9499 & -0.3400 & -0.4162 & 1 & -0.8286 \\
\hline $5 \mathrm{~F}$ & 1 & -0.8691 & 0.7326 & -0.6280 & 0.3532 \\
\hline \multicolumn{6}{|c|}{ Test and analysis results of free vibration proposed DIC method } \\
\hline Items & 1st mode & 2nd mode & 3rd mode & 4th mode & 5th mode \\
\hline Natural frequency & 1.0551 & 3.1610 & 5.0600 & 6.5700 & 7.5240 \\
\hline Damping ratio & 0.6270 & 0.6240 & 0.48931 & 0.4930 & 0.5860 \\
\hline \multicolumn{6}{|l|}{ Mode shape } \\
\hline Base & 0 & 0 & 0 & 0 & 0 \\
\hline $1 \mathrm{~F}$ & 0.3160 & 0.8390 & 1 & 0.9120 & 0.4421 \\
\hline $2 \mathrm{~F}$ & 0.5700 & 1 & 0.1650 & -0.9030 & -0.8260 \\
\hline $3 \mathrm{~F}$ & 0.7780 & 0.4770 & -0.9550 & -0.1430 & 1 \\
\hline $4 \mathrm{~F}$ & 0.9250 & -0.3740 & -0.4140 & 1 & -0.8513 \\
\hline $5 \mathrm{~F}$ & 1 & -0.9220 & 0.8060 & -0.6520 & 0.4180 \\
\hline
\end{tabular}

(b)

\begin{tabular}{|c|c|c|c|c|c|}
\hline \multicolumn{6}{|c|}{ Test and analysis results of Kobe earthquake record traditional accelerometer } \\
\hline Items & 1st mode & 2nd mode & 3rd mode & 4th mode & 5th mode \\
\hline Natural frequency & 1.0317 & 3.0969 & 5.0368 & 6.6412 & 7.6884 \\
\hline Damping ratio & 0.6373 & 0.4574 & 4.6337 & 2.8685 & 5.5449 \\
\hline \multicolumn{6}{|l|}{ Mode shape } \\
\hline Base & 0 & 0 & 0 & 0 & 0 \\
\hline $1 \mathrm{~F}$ & 0.3773 & 0.9008 & 1 & 0.8386 & 0.7390 \\
\hline $2 \mathrm{~F}$ & 0.6365 & 1 & 0.1596 & -0.7806 & -1 \\
\hline $3 \mathrm{~F}$ & 0.8256 & 0.4324 & -0.9755 & -0.2302 & 0.8620 \\
\hline $4 \mathrm{~F}$ & 0.9710 & -0.3862 & -0.3910 & 1 & -0.5846 \\
\hline $5 \mathrm{~F}$ & 1 & -0.8833 & 0.7546 & -0.6033 & 0.2264 \\
\hline \multicolumn{6}{|c|}{ Test and analysis results of Kobe earthquake record proposed DIC method } \\
\hline Items & 1st mode & 2nd mode & 3rd mode & 4th mode & 5th mode \\
\hline Natural frequency & 1.6292 & 3.1732 & 5.1040 & 6.5572 & 7.4244 \\
\hline Damping ratio & 0.5594 & 0.5271 & 3.952 & 2.9022 & 5.9642 \\
\hline \multicolumn{6}{|l|}{ Mode shape } \\
\hline Base & 0 & 0 & 0 & 0 & 0 \\
\hline $1 \mathrm{~F}$ & 0.3253 & 0.8001 & 0.9040 & 0.8371 & 0.7910 \\
\hline $2 \mathrm{~F}$ & 0.5783 & 1 & 0.2295 & -0.9281 & -1 \\
\hline $3 \mathrm{~F}$ & 0.7867 & 0.4750 & -1 & -0.2050 & 0.8232 \\
\hline $4 \mathrm{~F}$ & 0.9320 & -0.3711 & -0.3954 & 1 & -0.5547 \\
\hline
\end{tabular}


(b) Continued.

\begin{tabular}{|c|c|c|c|c|c|}
\hline $5 \mathrm{~F}$ & 1 & -0.9490 & 0.6543 & -0.4450 & 0.2641 \\
\hline \multicolumn{6}{|c|}{ Test and analysis results of El Centro 1940 earthquake record traditional accelerometer } \\
\hline Items & 1st mode & 2nd mode & 3rd mode & 4th mode & 5th mode \\
\hline Natural frequency & 1.0319 & 3.0975 & 5.0211 & 6.5905 & 7.6536 \\
\hline Damping ratio & 0.6953 & 0.3928 & 0.7949 & 1.5966 & 3.6372 \\
\hline \multicolumn{6}{|l|}{ Mode shape } \\
\hline Base & 0 & 0 & 0 & 0 & 0 \\
\hline $1 \mathrm{~F}$ & 0.3777 & 0.9028 & 1 & 0.9123 & 0.5205 \\
\hline $2 \mathrm{~F}$ & 0.6374 & 1 & 0.0868 & -0.9088 & -0.9208 \\
\hline $3 \mathrm{~F}$ & 0.8274 & 0.4325 & -0.9507 & -0.1363 & 1 \\
\hline $4 \mathrm{~F}$ & 0.9721 & -0.3865 & -0.3792 & 1 & -0.8075 \\
\hline $5 \mathrm{~F}$ & 1 & -0.8820 & 0.7432 & -0.6229 & 0.3449 \\
\hline \multicolumn{6}{|c|}{ Test and analysis results of El Centro 1940 earthquake record proposed DIC method } \\
\hline Items & 1st mode & 2nd mode & 3rd mode & 4th mode & 5th mode \\
\hline Natural frequency & 1.0623 & 3.1751 & 5.0911 & 6.9047 & 7.6536 \\
\hline Damping ratio & 0.5852 & 0.4331 & 0.8391 & 1.6671 & 3.6372 \\
\hline \multicolumn{6}{|l|}{ Mode shape } \\
\hline Base & 0 & 0 & 0 & 0 & 0 \\
\hline $1 \mathrm{~F}$ & 0.3210 & 0.8380 & 0.9830 & 0.9225 & 0.5205 \\
\hline $2 \mathrm{~F}$ & 0.5784 & 1 & 0.1070 & -0.9183 & -0.9208 \\
\hline $3 \mathrm{~F}$ & 0.7860 & 0.4683 & -1 & -0.1465 & 1 \\
\hline $4 \mathrm{~F}$ & 0.9321 & -0.3702 & -0.3341 & 1 & -0.8111 \\
\hline $5 \mathrm{~F}$ & 1 & -0.9210 & 0.8300 & -0.6914 & 0.3501 \\
\hline
\end{tabular}

two methods are slightly different; but the difference is not significant.

The analysis results shown in Figures 15 and 16 for structural cross-sectional dimensions of $360 \mathrm{~mm} / 400 \mathrm{~mm}$ and $280 \mathrm{~mm} / 400 \mathrm{~mm}$ subject to various types of earthquakes the ASDI values obtained by using these two methods are not much different. This confirms that as long as the building damage reaches a certain level, the method proposed in this research is capable of revealing the damage characteristics of the building subject to earthquake.

The white noise shown in Figure 17 shows the white noise for the ASDI obtained using the free vibration digital image method and the accelerometer method confirms that this method can really reveal the damage characteristics for the building subject to earthquake.

Figures 13-17 show that using the proposed index indices will clearly indicate the building damages and their sensitivity is dependent on the cross-sectional dimensions. When the column cross-sectional dimension is reduced by $80 \mathrm{~mm}$, the damage value is shown to increase obviously. If the column cross-sectional dimension is reduced by $20 \mathrm{~mm}$, the building damage characteristics cannot be shown. These figures also reveal that the damage index based on the natural vibration identifies modal parameter is not capable of deciding the location of building damage; however, the predicted degree of building damage due to external earthquake force is consistent. The damage indices obtained using the method proposed in this research and the conventional method have good correlations for the various column cross-sectional dimensions.

5.3. Analysis Results on IDMS-Based Damage Index. The Interstory Drift Mode Shape (IDMS) damage index is the interstory drift ratio before and after the earthquake (minus 1) for the first vibration mode that is based on the normalized value for a designated building story as the reference. In other words, the ratio of the normalized interstory drift versus the sensitivities before and after the damage is used as the basis; more damages correspond to higher sensitivities. Figures 18 and 19 show the sensitivity difference of this index for the data collected using the digital image method used in this research and the conventional accelerometer method. In Figure 18, when the degree of damage is $240 \mathrm{~mm} / 400 \mathrm{~mm}$, the free vibration IDMS using the method proposed in this research is $60 \%$ than that for the data collected using the traditional accelerometer. Comparing the data shown in Figure 18 with those shown in Figure 19 reveals that, when the structure is subject to the EL Centro 1940 earthquake records, the IDMS damage values obtained using both methods reach $60 \%$ for the damage level of $240 \mathrm{~mm} / 400 \mathrm{~m}$; hence, the sensitivity of the proposed method can be confirmed. Additionally, Figure 18 also shows that the conventional accelerometer method has worse sensitivity for lower degree of building damage. However, Figure 19 reveals that, when the building is subject to the EL Centro 1940 earthquake records and 


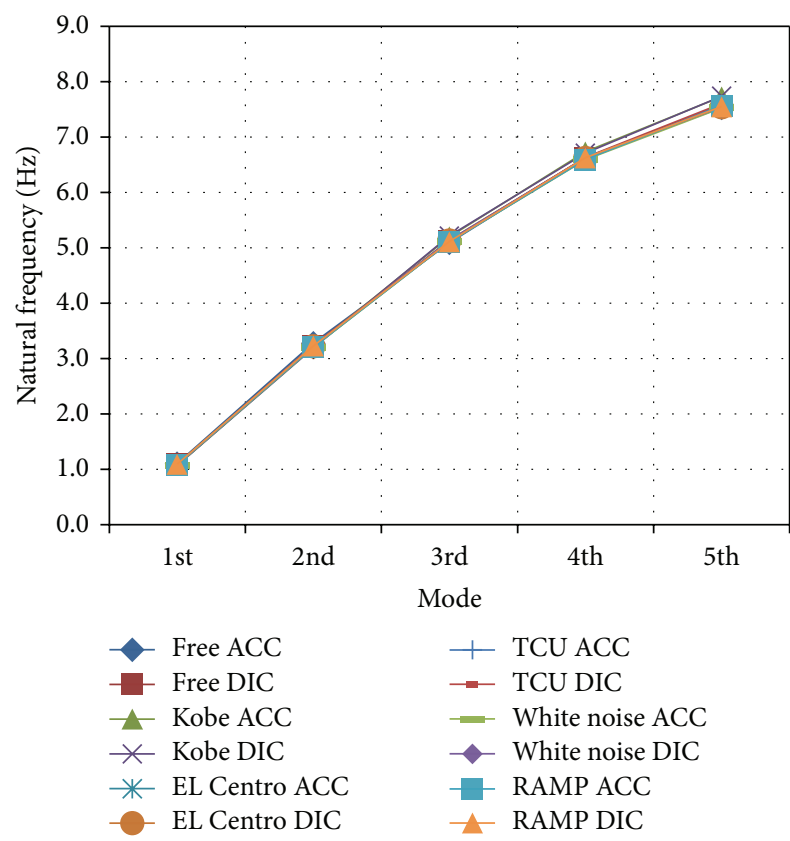

FIGURE 7: Comparisons of the identified building natural frequencies obtained using the method proposed in this research and the conventional method for cross-sectional dimensions of $400 \mathrm{~mm}$.

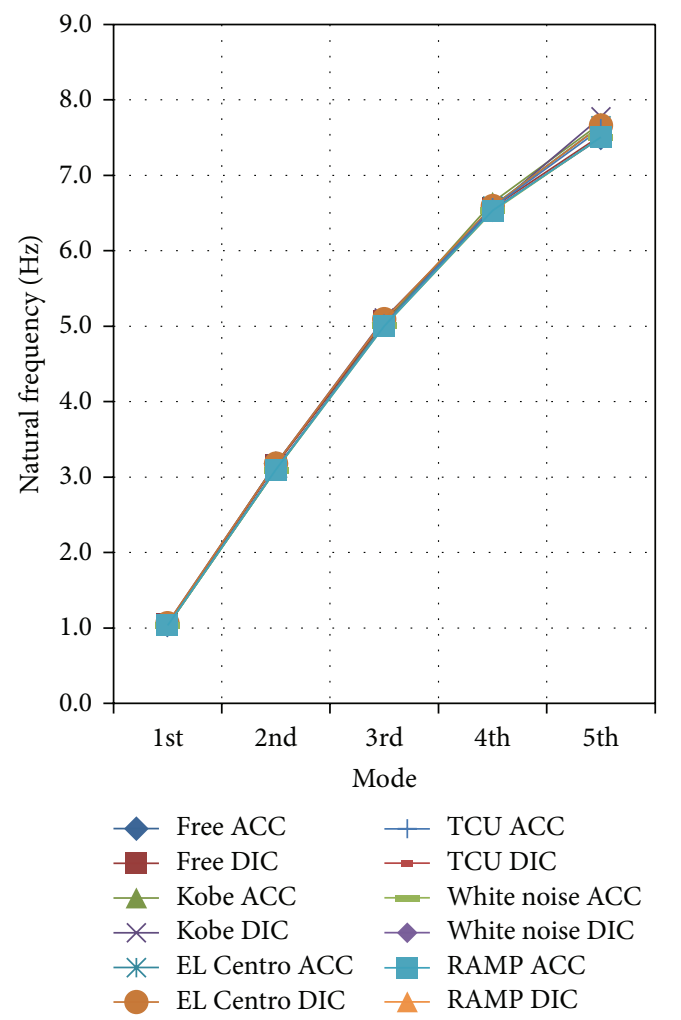

Figure 8: Comparisons of the identified building natural frequencies obtained using the method proposed in this research and the conventional method for cross-sectional dimensions of $380 \mathrm{~mm}$.

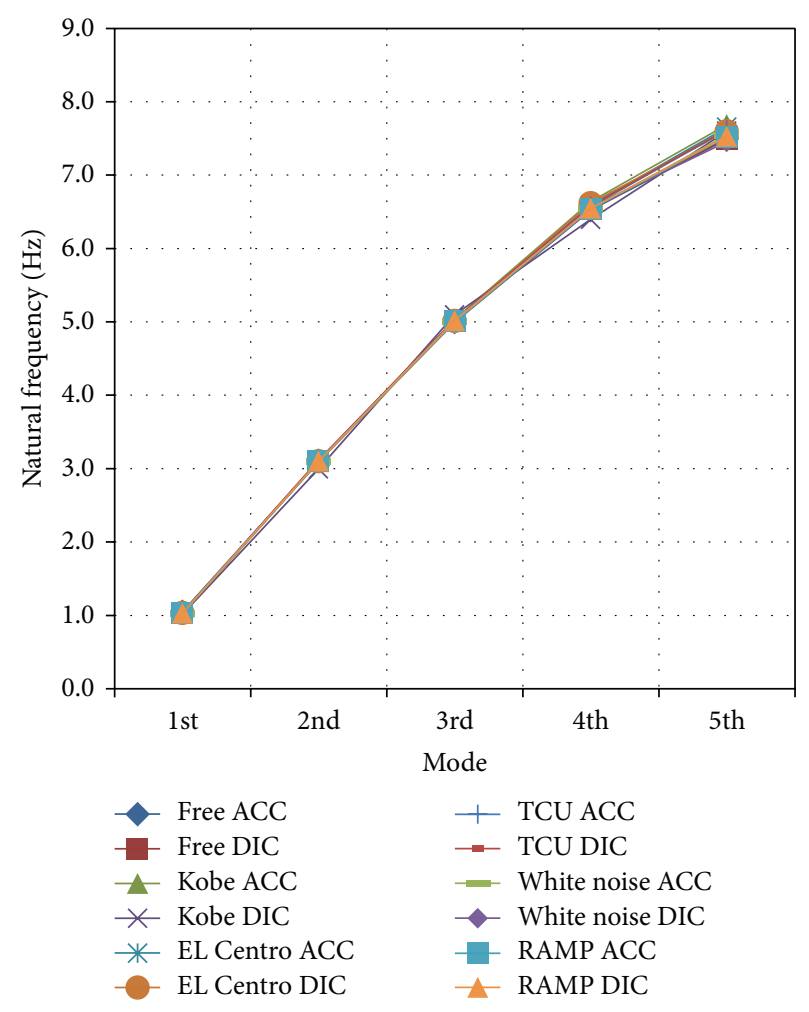

FIGURE 9: Comparisons of the identified building natural frequencies obtained using the method proposed in this research and the conventional method for cross-sectional dimensions of $360 \mathrm{~mm}$.

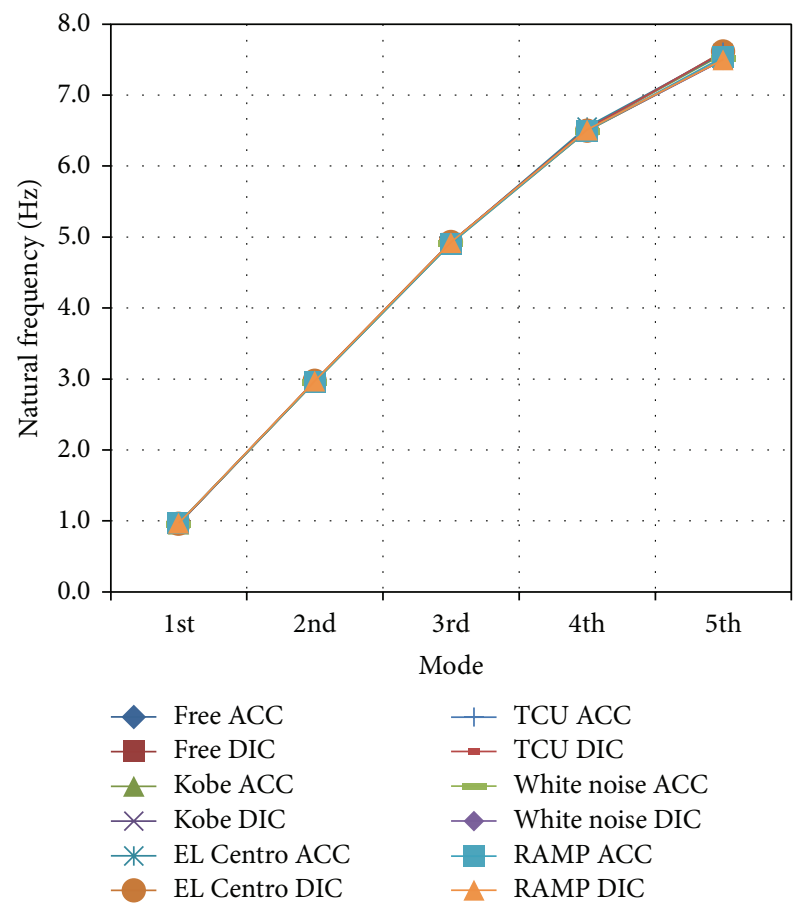

FIGURE 10: Comparisons of the identified building natural frequencies obtained using the method proposed in this research and the conventional method for cross-sectional dimensions of $280 \mathrm{~mm}$. 


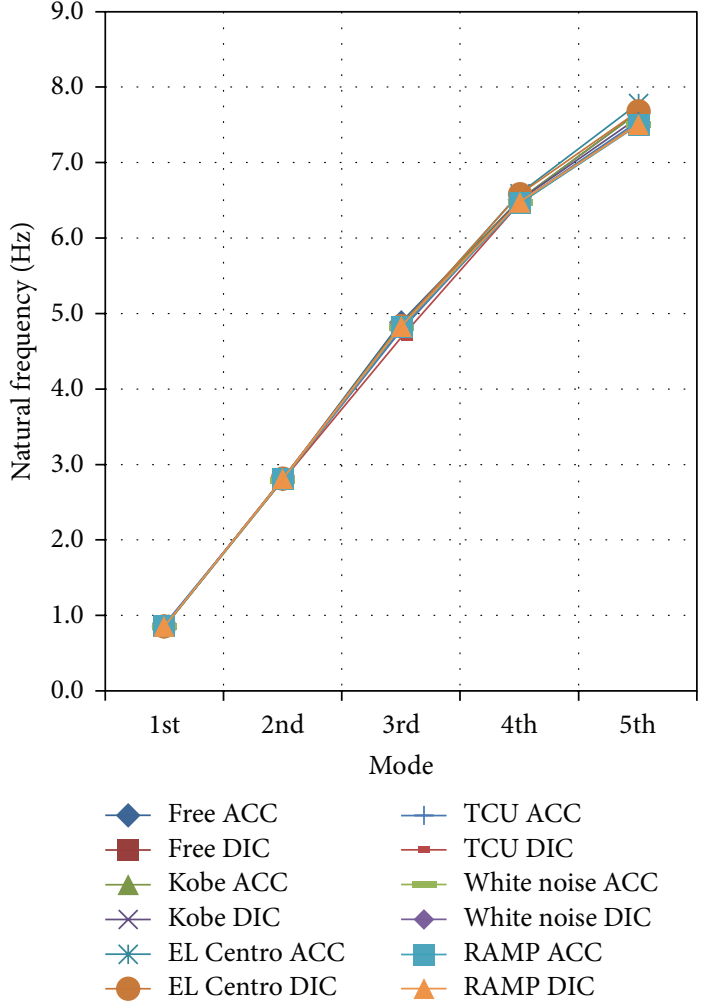

FIGURE 11: Comparisons of the identified building natural frequencies obtained using the method proposed in this research and the conventional method for cross-sectional dimensions of $200 \mathrm{~mm}$.

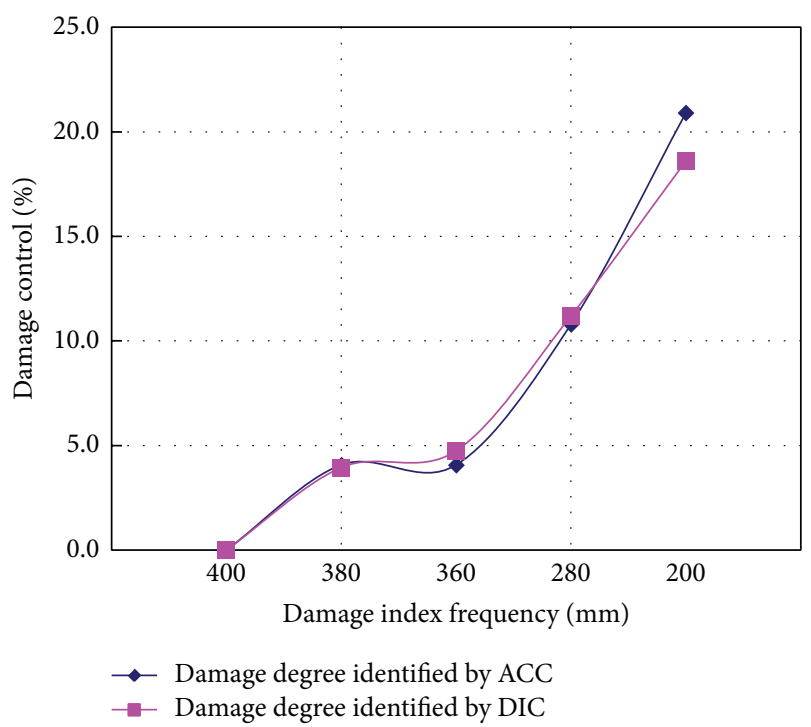

FIgURE 12: Damage index that is based on natural frequency for various stiffness.

the degree of damage is $380 \mathrm{~mm} / 400 \mathrm{~mm}$, this method has poor sensitivity. Hence, when the IDMS damage index is used to evaluate the building health, using different sensors to collect data will lead to the difference of sensitivity levels and the results of building health evaluation. However, this damage index is still capable of identifying the location of building story that suffers the damage. For various damages,

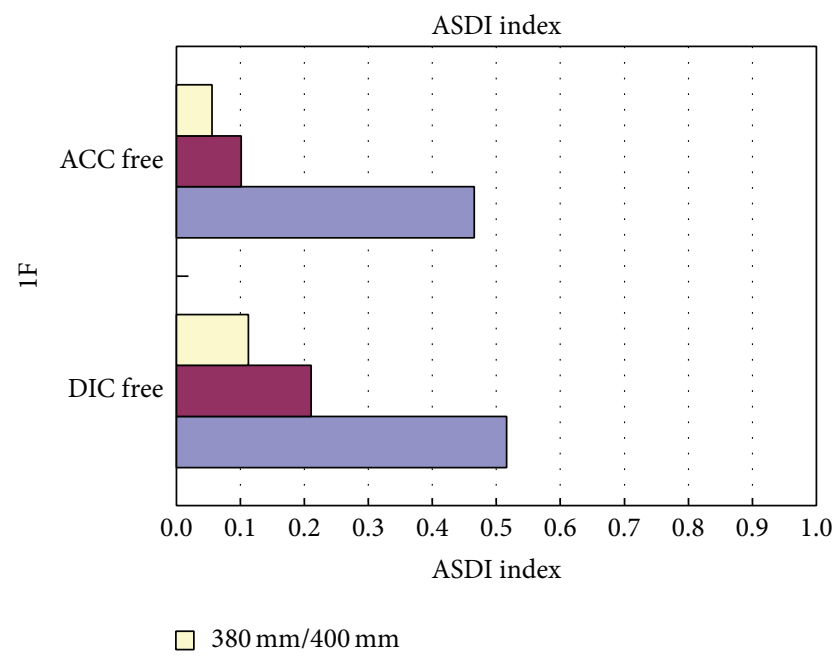

FIGURE 13: Comparisons of the ASDI-based damage indices for free vibration digital image method proposed in this research and the conventional accelerometer method.

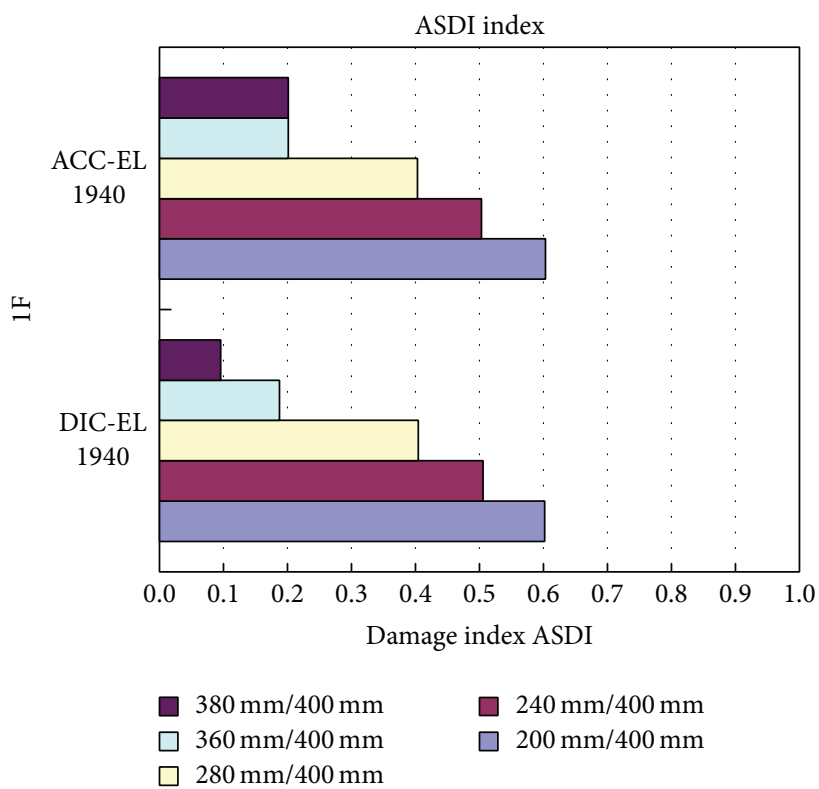

FIgURE 14: Comparisons of the ASDI-based damage indices using EL Centrol 1940 earthquake data as input for free vibration digital image method proposed in this research and the conventional accelerometer method.

of even less than $20 \mathrm{~mm}$ column cross-sectional reduction, the sensitivity difference can still be compared only if the sensor has certain accuracy for monitoring the displacement. Hence, the IDMS damage index is more suitable for the digital image method than the conventional accelerometer method.

Differences of the IDMS values for the building subject to EL Centro 1940, TCU, white noise, and RAMP with $360 \mathrm{~mm} / 400 \mathrm{~mm}$ of damage are evaluated in this research in order to understand the IDMS sensitivity when the building is subject to various modes of earthquake but suffers slight damages; it is shown in Figure 20. Under the 


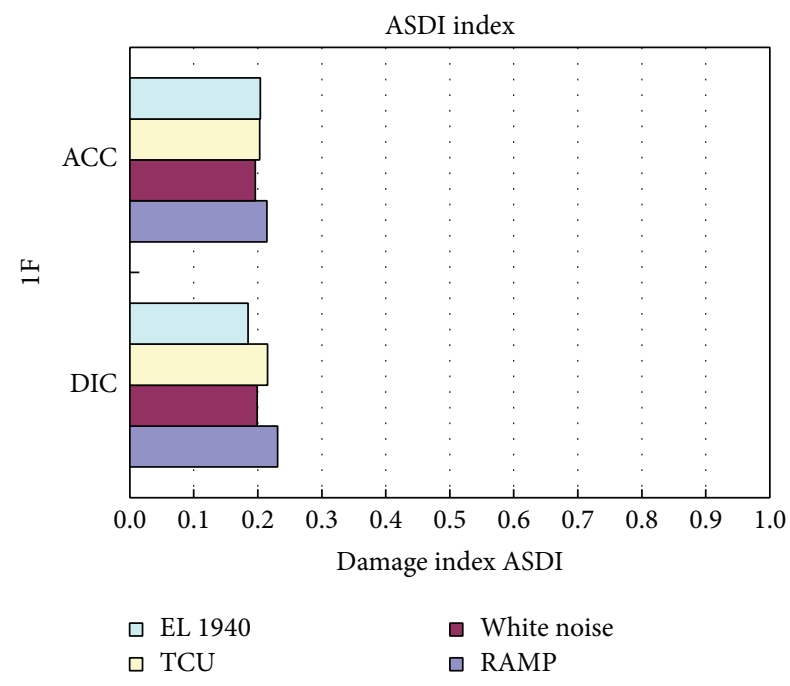

FIGURE 15: Comparisons of the ASDI-based damage indices for the free vibration digital image method as proposed in this research and the conventional accelerometer method (cross-sectional dimensions of $360 \mathrm{~mm}$ and $400 \mathrm{~mm}$ ).

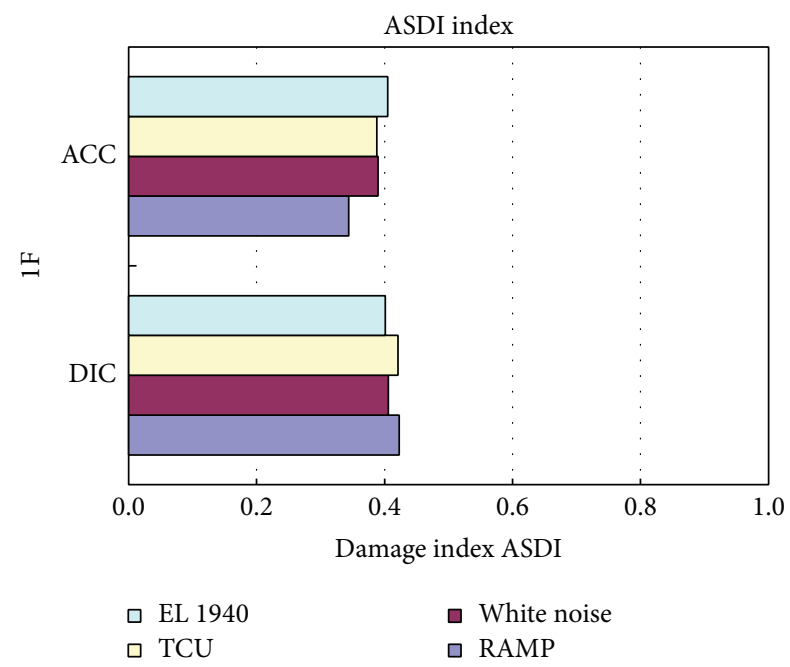

FIGURE 16: Comparisons of the ASDI-based damage indices for the free vibration digital image method as proposed in this research and the conventional accelerometer method (cross-sectional dimensions of $280 \mathrm{~mm}$ and $400 \mathrm{~mm}$ ).

influence of EL Centro 1940 and white noise, this method has lower sensitivity than the conventional accelerometer method; when the building is subject to TCU and RAMP earthquakes, both methods have comparable sensitivities, or this method sometimes has better sensitivity than the conventional method. Figure 21 shows that, when the structure is subject to EL Centro 1940, TCU, white noise, and RAMP types of earthquake with $280 \mathrm{~mm} / 400 \mathrm{~mm}$ of damage, the IDMS sensitivity for the this method is higher than that for the conventional method. These observations confirm that, when IDMS is used as the damage index for buildings with more serious damages, the method proposed in this research

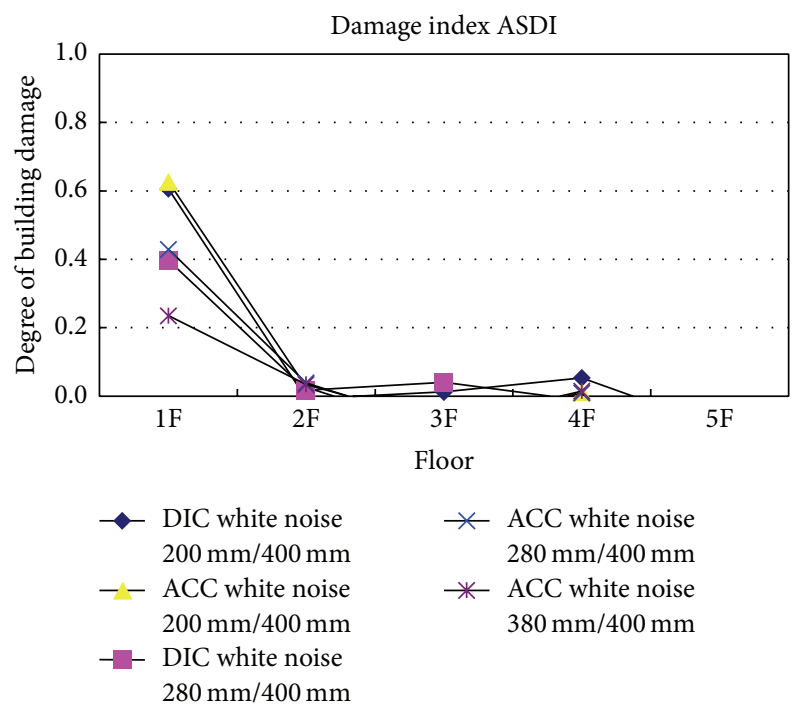

FIGURE 17: Comparisons of the white noise for the ASDI obtained using the digital image method and the accelerometer method.

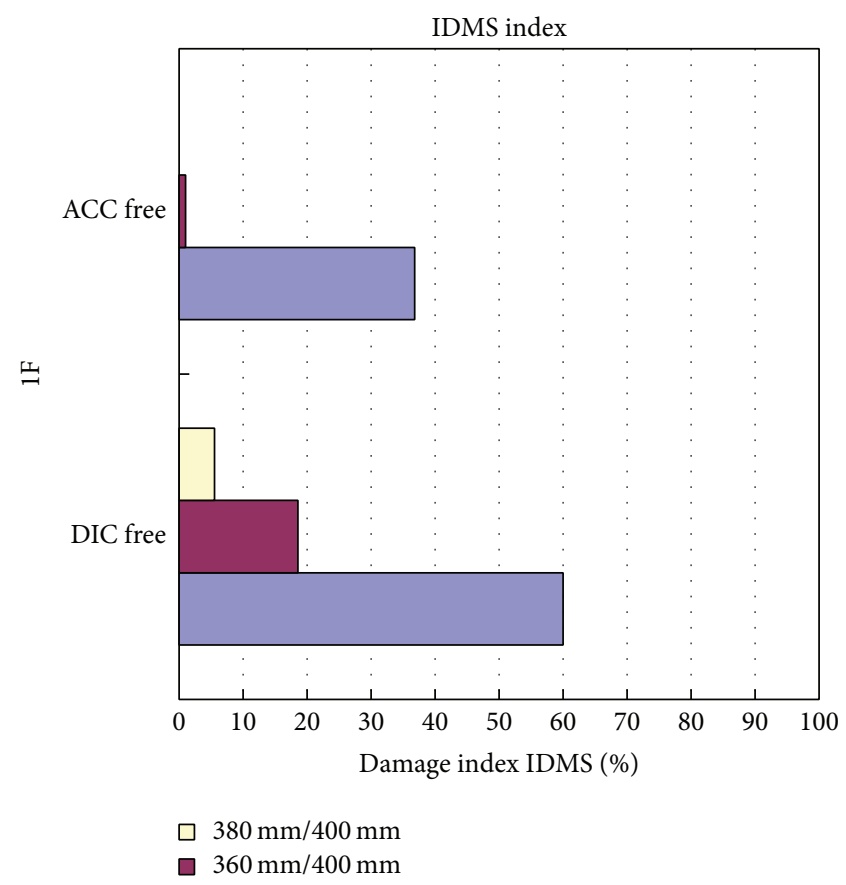

FIGURE 18: Comparisons of the IDMS damage indices based on the free vibration digital image method and the accelerometer method for building stories subject to different damage scales.

has a higher sensitivity to indicate the degree of building damage.

Comparisons of the ADSI and IDMS damage indices for buildings subject to EL Centro 1940 type earthquake with various degrees of damages are shown in Figures 22 and 23. In Figure 22, the ADSI damage indices are close for both digital image method and accelerometer method for various degrees of building damages; but there exist obvious differences between these two damage indices for the 


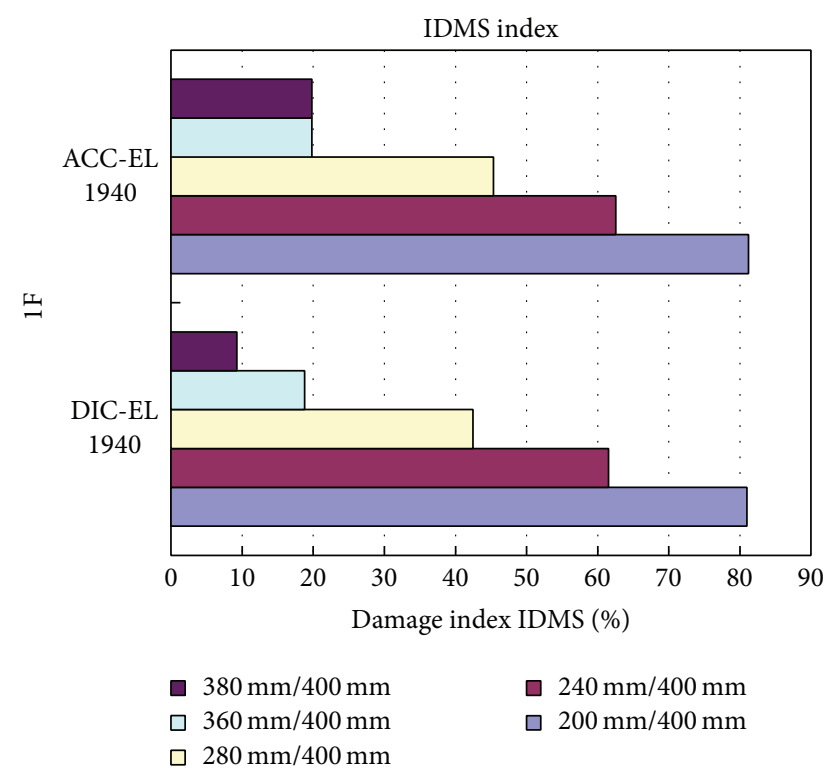

FIGURE 19: Comparisons of the IDMS damage indices based on the free vibration digital image method and the accelerometer method for building stories subject to the EL Centro 1940 earthquake data.

fifth story when the degree of damage is $200 \mathrm{~mm} / 400 \mathrm{~mm}$. Figure 23 shows that the IDMS damage index is capable of showing the degree of damage for the first story and similar degree of damage for other stories. However, for the 5th story, the IDMS is higher for the conventional accelerometer method than the digital image method. These two methods show similar IDMS values for the $3 \mathrm{rd}$ and the 4 th stories. Therefore, the above observations indicate that the IDMS index has higher sensitivity than the ADSI damage index and both indices are capable of showing the location of damage.

\section{Conclusions}

Results of this research confirm that the dynamic digital image analysis technology is capable of taking and analyzing dynamic images by way of detecting dynamic images to analyze the mechanical behavior of building under excitation of external force and the integrated technique for dynamic digital image devices. Laboratory studies confirm the accuracy and feasibility of the proposed method. Its implementation will assist in revealing the damage index of the building after it is subject to earthquake suffering from damages. The following conclusions are obtained as a result of a series of experimental studies.

(1) Improving the method to zero, the reference line will lead to good correlations between the results obtained using the method proposed in this research and the accelerometer method.

(2) The frequency variation is capable of predicting the building damages but is incapable of predicting the location of damage.

(3) The analysis results on ASDI-based damage index reveal that ASDI based on natural vibration identifies

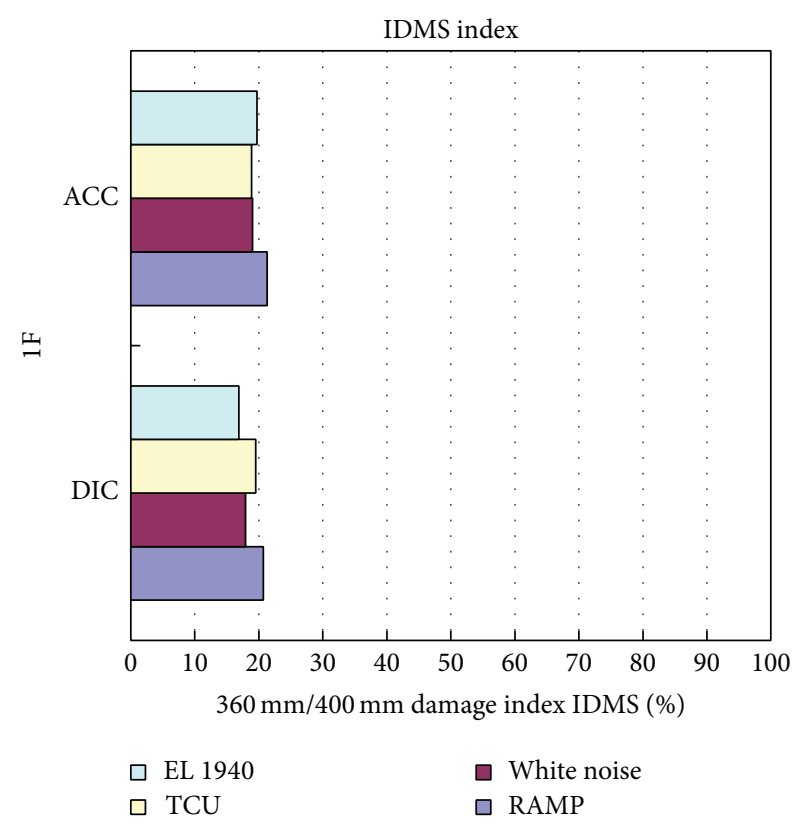

Figure 20: Comparisons of IDMS values using the digital image method and the accelerometer methods for building subject to various types of earthquakes with $360 \mathrm{~mm} / 400 \mathrm{~mm}$ of damages.

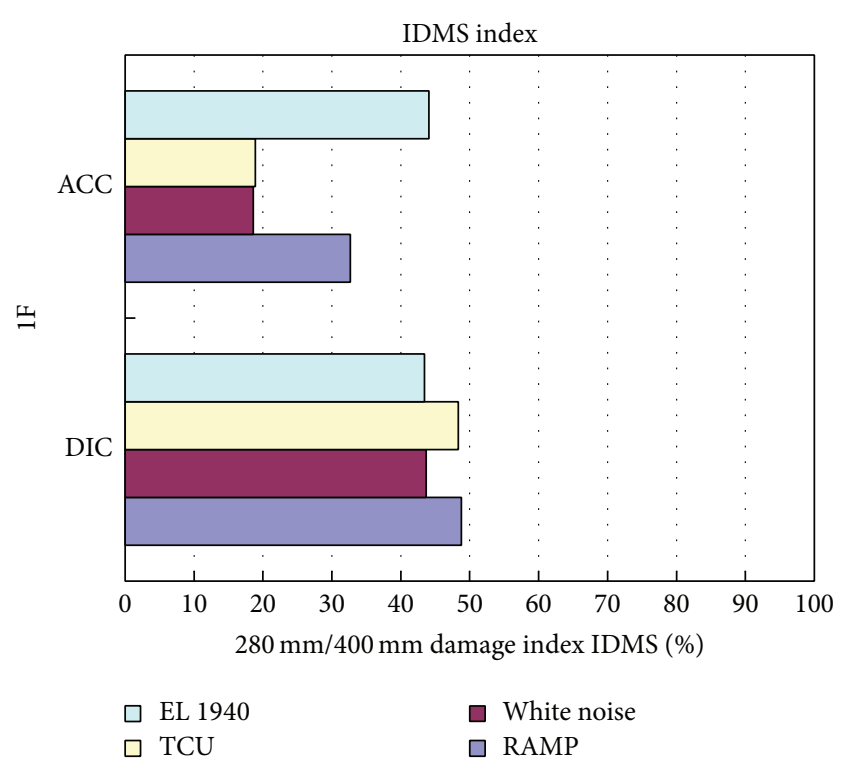

FIGURE 21: Comparisons of IDMS values using the digital image method and the accelerometer methods for building subject to various types of earthquakes with $280 \mathrm{~mm} / 400 \mathrm{~mm}$ of damages.

that the modal parameter is not capable of deciding the location of building damage. Nevertheless, this proposed method can be used to predict the degree of building damage due to external forces.

(4) Using IDMS damage index will lead to reveal the building story that suffers damages. However, the sensitivity becomes obvious when the structural crosssection becomes obviously thinner to increase the 

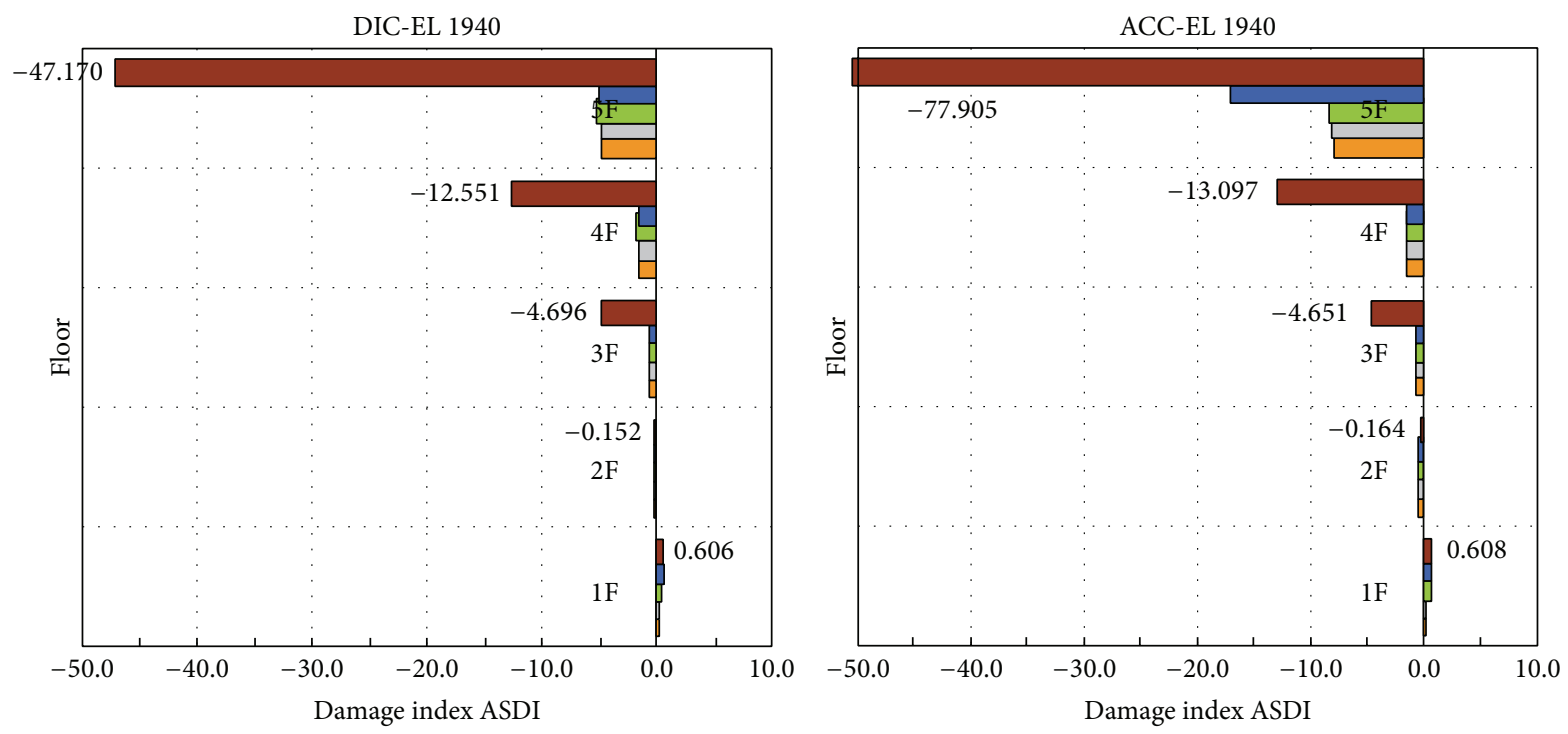
$380 \mathrm{~mm} / 400 \mathrm{~mm}$
$240 \mathrm{~mm} / 400 \mathrm{~mm}$
$360 \mathrm{~mm} / 400 \mathrm{~mm}$
- $200 \mathrm{~mm} / 400 \mathrm{~mm}$
ㄷ $280 \mathrm{~mm} / 400 \mathrm{~mm}$

$380 \mathrm{~mm} / 400 \mathrm{~mm}$

$240 \mathrm{~mm} / 400 \mathrm{~mm}$

$360 \mathrm{~mm} / 400 \mathrm{~mm}$

- $200 \mathrm{~mm} / 400 \mathrm{~mm}$

FIGURE 22: Comparisons of the ADSI damage index of various building stories based on the digital image method and the accelerometer method for building subject to the EL Centro 1940 earthquake data.
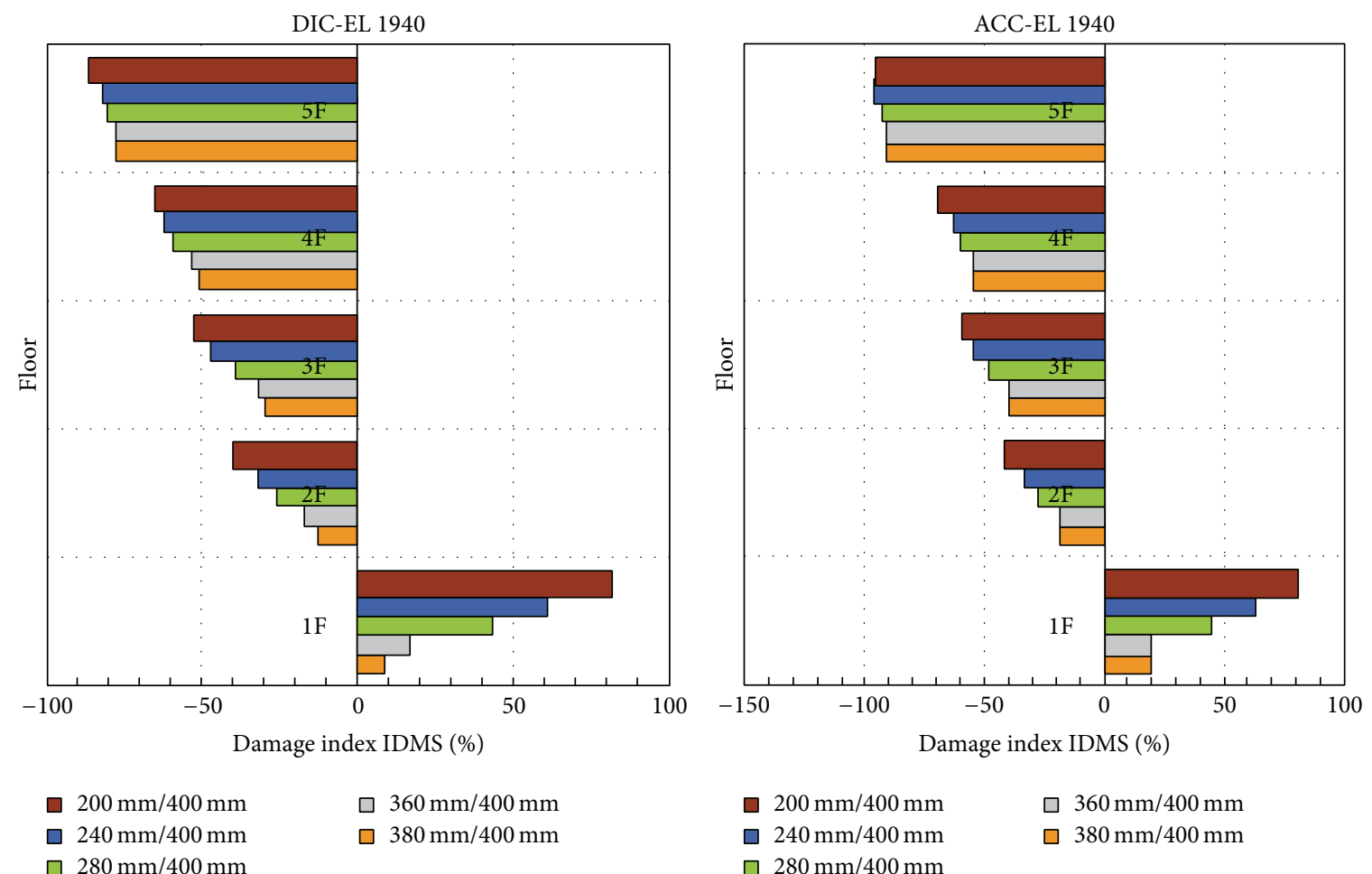
$\square 200 \mathrm{~mm} / 400 \mathrm{~mm}$
$\square 360 \mathrm{~mm} / 400 \mathrm{~mm}$
口 $240 \mathrm{~mm} / 400 \mathrm{~mm}$
$\square 380 \mathrm{~mm} / 400 \mathrm{~mm}$

FIGURE 23: Comparisons of the IDMS damage index of various building stories based on the digital image method and the accelerometer method for the building subject to the EL Centro 1940 earthquake data. 
damage value. If the building column cross-section becomes slightly thinner, the damage index is not capable of revealing the building damage characteristics.

(5) If coped with the IDMS damage index, this method is capable of expressing the degree of damage caused when the building suffers a higher degree of damage caused by earthquake.

\section{Conflict of Interests}

The authors declare that there is no conflict of interests regarding the publication of this paper.

\section{Acknowledgment}

The authors would like to acknowledge the support of Taiwan National Science Council through Grant no. NSC-100-2625M-260-001.

\section{References}

[1] http://en.wikipedia.org/wiki/2004_Indian_Ocean_earthquake_ and_tsunami.

[2] http://translate.google.com.tw/translate?hl=zh-TW\&langpair= en\%7Czh-TW\&u=http://en.wikipedia.org/wiki/2011_T\%25C5 \%258Dhoku_earthquake_and_tsunami.

[3] S. N. Pakzad, G. L. Fenves, S. Kim, and D. E. Culler, "Design and implementation of scalable wireless sensor network for structural monitoring," Journal of Infrastructure Systems, vol. 14, no. 1, pp. 89-101, 2008.

[4] M. J. Whelan and K. D. Janoyan, "Design of a robust, high-rate wireless sensor network for static and dynamic structural monitoring," Journal of Intelligent Material Systems and Structures, vol. 20, no. 7, pp. 849-863, 2009.

[5] M. Krommer, M.Zellhofer, and K.-H. Heilbrunner, "Strain-type sensor networks for structural monitoring of beam-type structures," Journal of Intelligent Material Systems and Structures, vol. 20, no. 15, pp. 1875-1888, 2009.

[6] B. Chen and W. Liu, "Mobile agent computing paradigm for building a flexible structural health monitoring sensor network," Computer-Aided Civil and Infrastructure Engineering, vol. 25, no. 7, pp. 504-516, 2010.

[7] Z. Qiu, J. Wu, and S. Yuan, "A wireless sensor network design and evaluation for large structural strain field monitoring," Measurement Science and Technology, vol. 22, no. 7, Article ID 075205, 2011.

[8] S. K. T. Grattan, S. E. Taylor, P. M. A. Basheer, T. Sun, and K. T. V. Grattan, "Sensors systems, especially fibre optic sensors in structural monitoring applications in concrete: an overview," in New Developments in Sensing Technology for Structural Health Monitoring, vol. 96 of Lecture Notes in Electrical Engineering, pp. 359-425, 2011.

[9] V. A. Tran, S. T. Quek, and W. H. Duan, "Sensor validation in damage locating vector method for structural health monitoring," International Journal of Structural Stability and Dynamics, vol. 11, no. 1, pp. 149-180, 2011.

[10] F. Federici, F. Graziosi, M. Faccio et al., "An integrated approach to the design of wireless sensor networks for structural health monitoring," International Journal of Distributed Sensor Networks, vol. 2012, Article ID 594842, 16 pages, 2012.

[11] S. K. Ghorai and D. Ranjan Roy, "Sensor development life cycle of embedded fiber bragg grating sensor for structural health monitoring," Journal of Structural Engineering, vol. 38, no. 5, pp. 428-438, 2011.

[12] T. Yi, H. Li, and M. Gu, "Recent research and applications of GPS-based monitoring technology for high-rise structures," Structural Control and Health Monitoring, vol. 20, no. 5, pp. 649670, 2013.

[13] T. Yi, H. Li, and M. Gu, "Wavelet based multi-step filtering method for bridge health monitoring using GPS and accelerometer," Smart Structures and Systems, vol. 11, no. 4, pp. 331-348, 2013.

[14] T. Yi, H. Li, and M. Gu, "Characterization and extraction of global positioning system multipath signals using an improved particle-filtering algorithm," Measurement Science and Technology, vol. 22, no. 7, Article ID 075101, 2011.

[15] W. Sung, V. C. Matzen, and M. Shih, "Time domain system identification of unknown initial conditions," Journal of Zhejiang University: Science, vol. 5, no. 9, pp. 1035-1044, 2004.

[16] J. Wang, C. Lin, and S. Yen, "A story damage index of seismically-excited buildings based on modal frequency and mode shape," Engineering Structures, vol. 29, no. 9, pp. 21432157, 2007.

[17] P. G. Bakir, "The combined deterministic stochastic subspace based system identification in buildings," Structural Engineering and Mechanics, vol. 38, no. 3, pp. 315-332, 2011.

[18] E. Reynders, "System identification methods for (operational) modal analysis: review and comparison," Archives of Computational Methods in Engineering: State of the Art Reviews, vol. 19, no. 1, pp. 51-124, 2012.

[19] S. Tung, M. Shih, and W. Sung, "Development of digital image correlation method to analyse crack variations of masonry wall," Sadhana, vol. 33, no. 6, pp. 767-779, 2008.

[20] M. H. Shih, W. P. Sung, S. H. Tung, D. Bacinskas, and G. Kaklauskas, "Developing three-dimensional digital image correlation techniques to detect the surface smoothness of construction materials," International Journal of Materials and Product Technology, vol. 42, no. 3-4, pp. 234-246, 2011.

[21] J. N. Juang, Applied System Identification, Prentice-Hall, Englewood Cliffs, NJ, USA, 1994. 

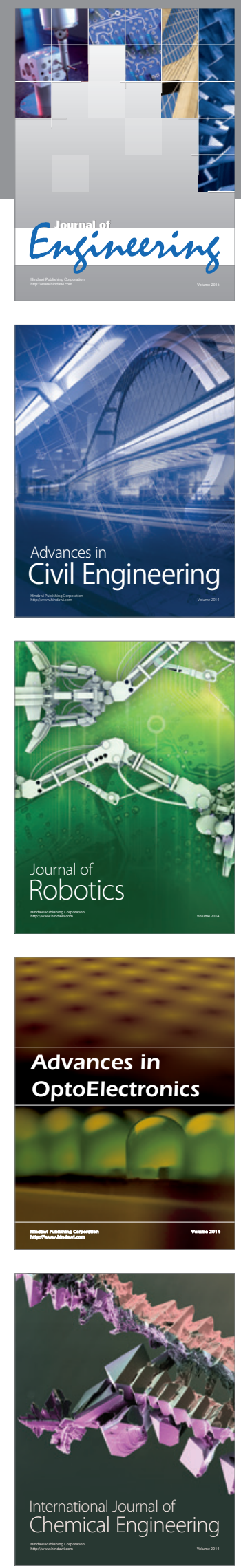

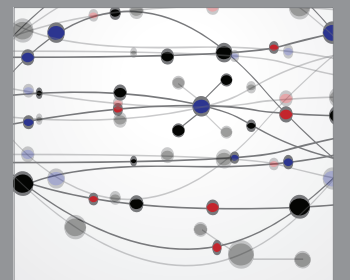

The Scientific World Journal
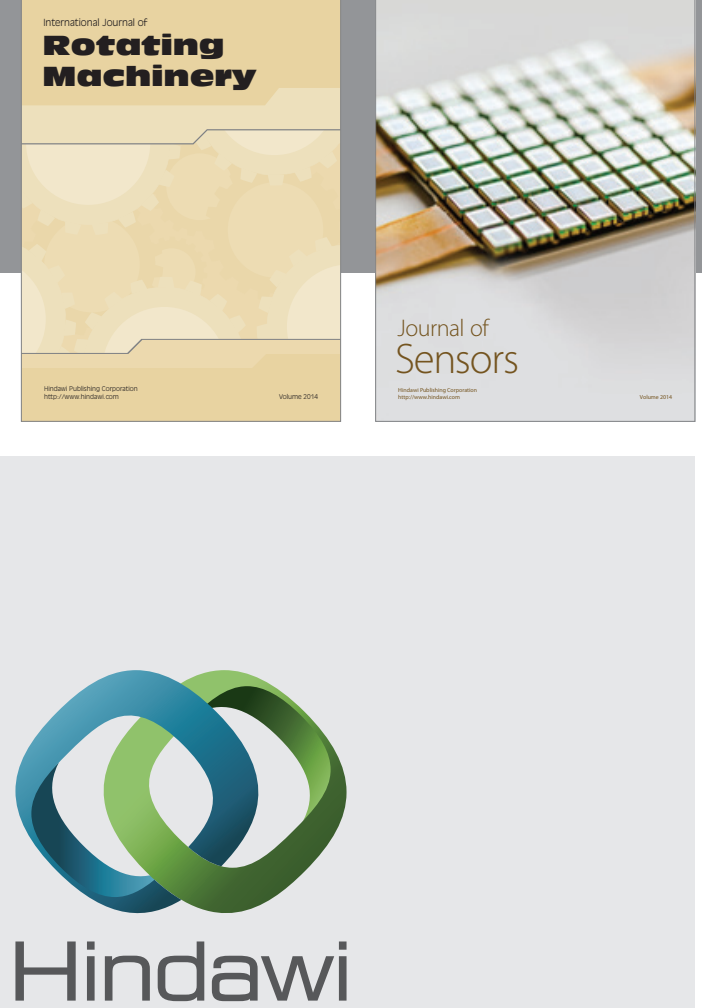

Submit your manuscripts at http://www.hindawi.com
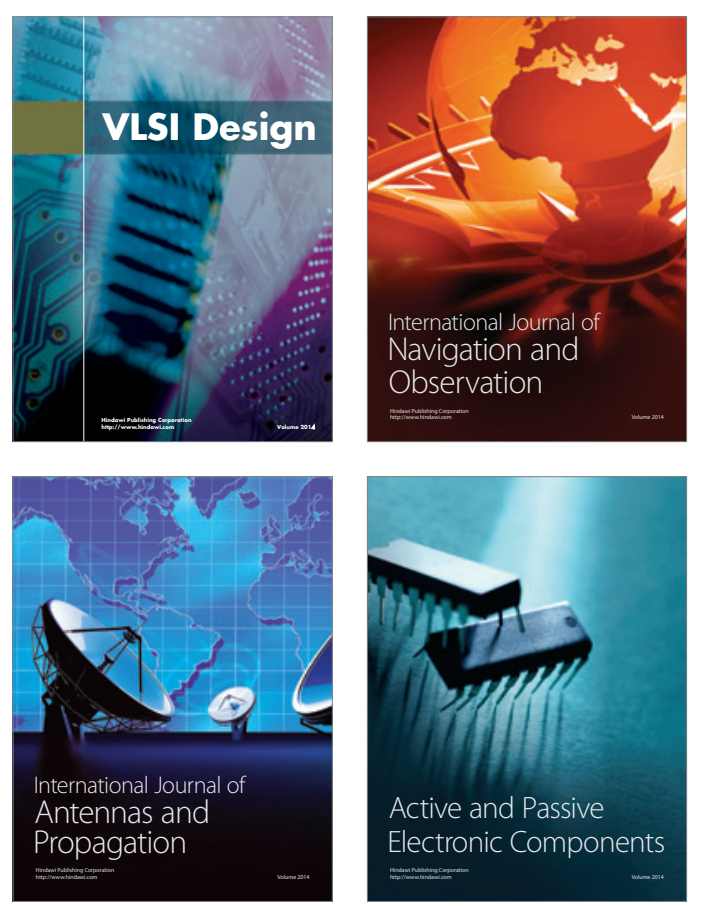
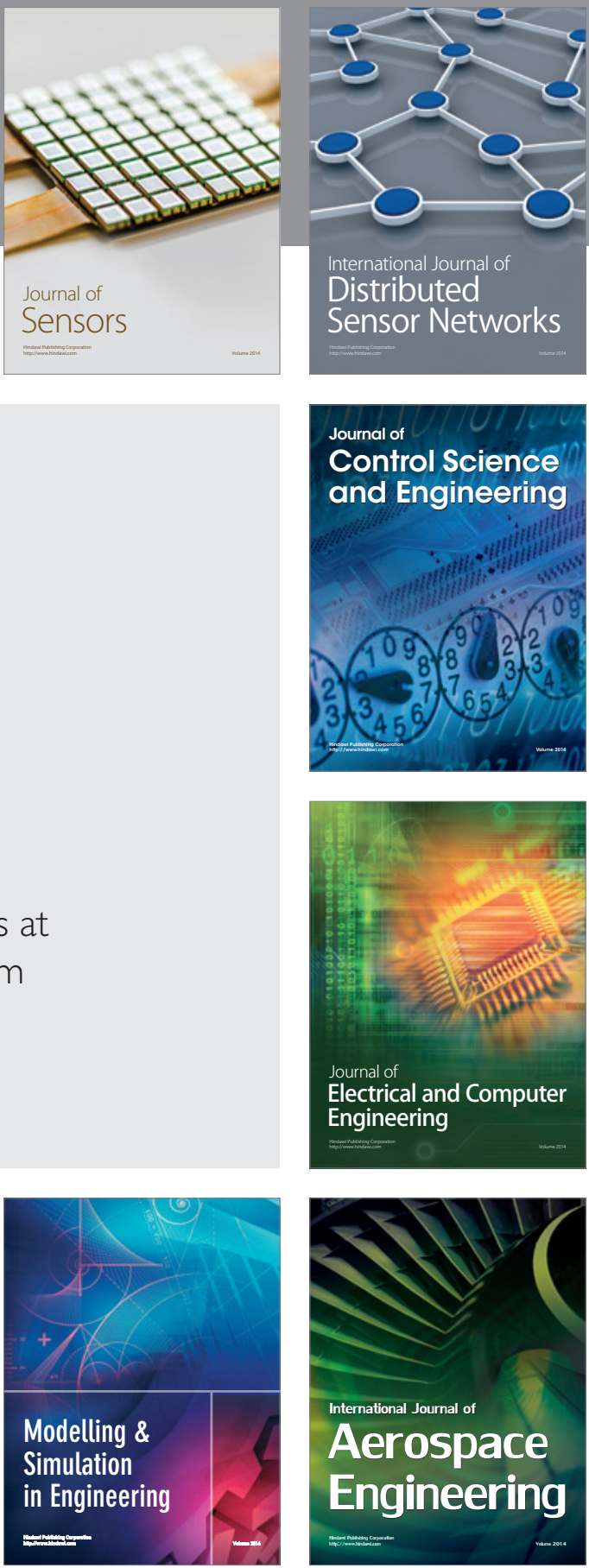

Journal of

Control Science

and Engineering
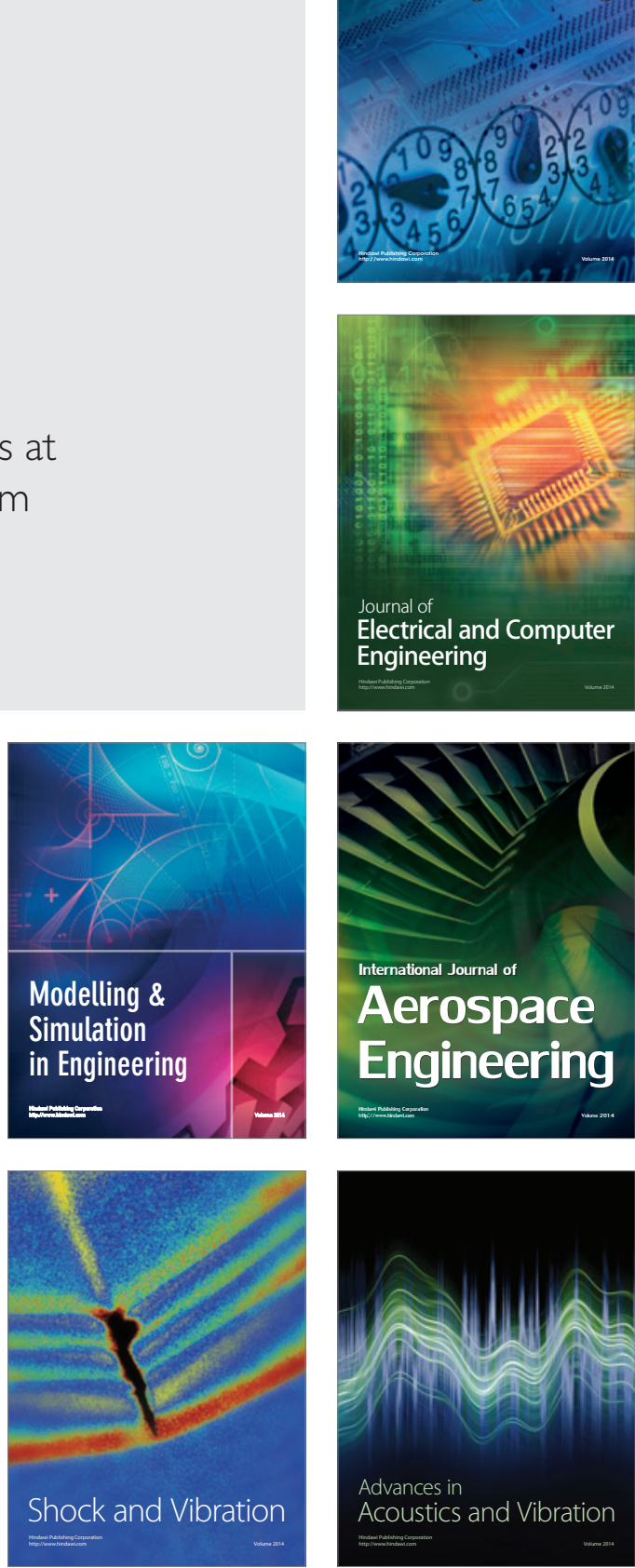